\title{
Failure Analysis of Discrete Damaged Tailored Extension- Shear-Coupled Stiffened Composite Panels
}

\author{
Donald J. Baker* \\ Vehicle Technology Directorate - ARL, NASA Langley Research Center, Hampton, VA 23681
}

\begin{abstract}
The results of an analytical and experimental investigation of the failure of composite Istiffener panels with extension-shear coupling are presented. This tailored concept, when used in the cover skins of a tiltrotor aircraft wing has the potential for increasing the aeroelastic stability margins and improving the aircraft productivity. The extension-shear coupling is achieved by using unbalanced $\pm 45^{\circ}$ plies in the skin. The failure analysis of two tailored panel configurations that have the center stringer and adjacent skin severed is presented. Finite element analysis of the damaged panels was conducted using STAGS (STructural Analysis of General Shells) general purpose finite element program that includes a progressive failure capability for laminated composite structures that is based on point-stress analysis, traditional failure criteria, and ply discounting for material degradation. The progressive failure predicted the path of the failure and maximum load capability. There is less than 12 percent difference between the predicted failure load and experimental failure load. There is a good match of the panel stiffness and strength between the progressive failure analysis and the experimental results. The results indicate that the tailored concept would be feasible to use in the wing skin of a tiltrotor aircraft.
\end{abstract}

\section{Introduction}

One of the principal design challenges for high-speed tiltrotor transport aircraft is achieving acceptable proprotor aeroelastic stability margins, which can restrict the operating airspeed of the tiltrotor aircraft in the high-speed airplane mode. The primary mechanism responsible for the proprotor stability problems is discussed by Popelka, et $\mathrm{al}^{1}$ and will be briefly reviewed here. Historically, the most critical modes affecting the proprotor stability are the symmetric wing beamwise bending (SWB) mode and the symmetric wing chordwise (SWC) bending mode. For these modes, the proprotor can create destabilizing in-plane hub forces, which can overcome the structural and aerodynamic damping of the wing at high speed and resulting in instability. The in-plane shear forces are generated by the proprotor in response to the pylon pitch angle perturbation and pitch rate. The wing SWB mode, SWC mode and symmetric wing torsion (SWT) mode dictate the pylon pitch rate and pitch angle. Proprotor stability can be influenced by changing the frequency placement of the wing modes and by modifying the mode shapes to alter the pylon dynamic response and reduce the destabilizing in-plane hub forces.

In a typical tiltrotor wing design, the rotor pylon pitches up as the wing bends upward in the SWB mode. To increase the stability boundary it is necessary to minimize the pylon pitch motion $(\theta)$ in the fundamental wing mode to increase the proprotor stability by reducing the rotor destabilizing forces as shown in Fig. 1. For a conventional tiltrotor composite wing design with structurally balanced skin laminates, the wing provides no structural pitch/bending coupling to resist the nose up pitch due to pylon mass offsets. Unbalanced composite skins, on the other hand, can create nose down structural twist as the wing bends upward to offset the pitch up tendency from the pylon mass offsets. The net effect is reduced pitch/bending $(\theta / z)$ coupling and improved stability. The preceding discussion applies to the SWB mode only.

The effects of structural tailoring can be simply shown by considering the cantilever boxbeam shown as the model in Fig. 2. The direction of the $-45^{\circ}$ plies are shown on Fig. 2. The forward and aft spar web is a balanced $\pm 45^{\circ}$ laminate. The upward bending from the pylon produces a compression load in the upper skin and a tension load in the lower skin as shown in Fig. 2. The compression load in the upper skin produces an in-plane deflection in the forward direction. The tension load in the lower skin produces an in-plane deflection in aft direction. These in-

\footnotetext{
*Aerospace Engineer, Mechanics of Structures and Materials Branch, MS 150, Langley Research Center.
} 
plane deflections in the skins combine to produce a couple that results in a nose down pitch as shown in the deformed model in Fig. 2.

The feasibility of a composite tailored wing for a high-speed civil tiltrotor transport aircraft has been addressed by Popelka, ${ }^{2}$ et al, using current analytical methods to design a tailored composite wing for a tiltrotor transport aircraft. Parametric studies indicate that the overall stability gains from composite tailoring can be limited because of conflicting structural design requirements imposed by the two critical modes of instability, SWB and SWC, and the necessity to balance the stability boundaries for both modes. The SWC mode stability can be improved by increasing the chordwise bending stiffness of the wing. The final tailored transport wing configuration from Reference [3] was a three-stringer configuration with a $70 / 30$ blend ratio of $-45^{\circ} /+45^{\circ}$ plies for the skin laminate along with stringer cap and spar cap tailoring to improve the SWC mode.

A 1/5-scale wing model was designed to have the same elastic characteristics as the full-scale tailored wing and was tested in a semi-span aeroelastic model to demonstrate that composite tailoring techniques can be used to improve proprotor stability ${ }^{3}$. A direct comparison between the baseline and tailored composite wing stability boundaries indicates an increase over baseline of approximately 30 knots in the scaled model or 58 knots in the fullscale design. For a full-scale design, the 58 knot increase in the stability boundary represents a significant improvement.

Recent work has assessed the detailed structural response of tailored panels with and without damage. Specifically, this work addressed: a) development of a test method for testing elastically coupled specimens and b) demonstration of the coupled response of the full-scale wing panel subcomponents with and without impact and discrete source damage. The analytical and experimental results of the study are presented in Reference [4] and illustrate the predictive capability for stiffened, anisotropic panels.

The present paper will summarize the failure analysis of the two panels configurations reported in Reference [4] that have discrete source damage. Specifically, this research addresses: a) utilization of a progressive failure analysis method, and b) comparison of the predicted failure mode with the actual test results. A method of recording the full field displacements at timed intervals during the testing is utilized and will be verified using standard measurement techniques. The analytical and experimental results of the study are presented and compared to illustrate the predictive capability for stiffened, anisotropic panels.

\section{Test Specimens and Test Method}

The panels to be evaluated were designed by Bell Helicopter, Textron, using the results of the study by Popelka, ${ }^{2}$ et, al and are shown in Fig. 3a. A cross-section of the stiffener and skin is shown in Fig. 3b. The skin is 21 plies increasing to 47 plies under the I-stiffener using Grade 190 IM6-3501-6 carbon-epoxy tape material. The skin orientation is $\left[45 / 90 /-45_{3} / 45 /-45_{3} / 45 / \overline{0}\right]_{\mathrm{s}}$ where $67 \%$ of the $45^{\circ}$ plies are oriented at the negative angle. The ply orientation for the reinforced area under the stiffener is $\left[45 / 90 /-45_{3} / 45 / \mathrm{a} / 0_{3} / \mathrm{a} /-45_{2} / \mathrm{a} / 0_{4} / \mathrm{a} /-45 / 45 / 0 / 45 /-45 / \mathrm{a} / 0_{4} / \mathrm{a} /-\right.$ $\left.45_{2} / \mathrm{a} / \mathrm{O}_{3} / \mathrm{a} / 45 /-45_{3} / 90 / 45 / \mathrm{a} / 45^{\mathrm{f}} /-45^{\mathrm{f}} / \mathrm{a}\right]$. Where "a" identifies a 0.008 -inch-thick layer of FM300 adhesive. The Istiffener is fabricated from back-to-back C-channels which have the following layup: $\left[-45 / 90_{2} / 45 / 0_{4} /-45 / 0_{4} / 45 /\right.$ $\left.0_{4} / 45 / 0_{2}\right]$. The cap of the I-stiffener has a layup of $\left[0_{2} /-45 / 0_{4} /-45 / 0_{4} / 45 / 0_{4} /-45 / 90_{2} / 45\right]$. The material for the stiffener and cap is Grade 95 IM6-3501-6 carbon-epoxy material. The stringer spacing is 7.5 inches, which gives an overall panel width of approximately 19 inches.

Four 4-foot-long panels, as shown in Fig. 3a, were manufactured at two different times. These panels were cut into 23-inch-long test specimens, potted and ground flat and parallel for testing. Panels TP-1 through TP-4 were manufactured from the first fabrication run and panels TP-5 through TP-8 were manufacture from the second manufacturing run. Panels TP-4 and TP-7 were selected to have discrete damage by machining a slot through the center stiffener and adjacent skin. The slot extends from the center of each skin panel and is 0.38 -inch-wide in the center of the specimen tapering to 0.18 -inch-wide at the ends with a tip radius of 0.09 -inch. These panels will be identified as Horizontal cut panels. Panel TP-5 also had the center stiffener cut similar to the Horizontal cut panels except the cut was rotated $15^{\circ}$ from the horizontal and will be identified as an Inclined cut panel. Photographs of the test specimens are shown in Fig.4.

All specimen tests were performed at room temperature, with no prior environmental conditioning. The specimens were placed between the platens of a 600 kip or 1200 kip hydraulic test machine and loaded at $5 \mathrm{kips} / \mathrm{min}$ in compression until failure. The load, strain, out-of-plane and head displacements were recorded with a computercontrolled data acquisition system for each test. The VIC-3D system is also computer controlled for acquiring the images and load at timed intervals. 


\section{Instrumentation}

Three measurement techniques were utilized to determine the response of these panels:

Strain gages - Common off the shelf strain gages were used on the panels. Both the panel configurations contained the same number of gages. Five axial gages (numbers 1, 2, 3, 13 and 14) were located on the stringer caps - one gage was located on each stringer at the quarter point of the panel length and one gage was located on the outside stringers at the panel midpoint. One rosette gage was located on each skin panel centerline and at the quarter point length, on the stringer side. Three axial gages (numbers 4, 5 and 6) were located on the skin side at the quarter point length opposite the axial gages on the stringer caps. One strip gage with 10 gages was located at each end of the slot. The strip gage was located horizontally, on the stringer side, on each panel configuration. Most of the strain gages can be seen in Fig.4.

Displacement transducers - Two Linear Variable Displacement Transducers (LVDT) were located between the test machine platens to measure the panel end shortening Six LVDT's were utilized to measure the out-of-plane displacements at panel centerline. Four LVDT's were located on the stringers and two LVDT's were located at the skin panel centerline.

Three-dimensional Video Correlation System (VIC-3D) - This system is a full-field-displacement measurement technique [5] that utilizes a camera-based stereo-vision system. VIC- $3 \mathrm{D}^{\dagger}$ is a non-intrusive system that uses a contrasting speckle pattern (e.g., black and white paint) applied to the specimen to provide dense features that can accurately be tracked between different cameras and during deformation. Images of the changing pattern on the test specimen surface are recorded on a computer with the stereo-vision system at user specified time intervals. It is also possible to take data in a local area, e.g., in the vicinity of a notch, with a second camera based system while taking data on a global area. This will give higher resolution to the displacements in the local area of interest.

The strain gages were located on the back side of the damaged panels to allow approximately 60 percent of the skin surface free for the application of a 0.004-inch-thick white vinyl contact paper that has been printed with a random black spackle pattern. A 4.0-inch by 4.0-inch area was selected at one tip of the slot for the local area of interest. The first step in panel preparation was to prepare an area larger than the selected local area with white paint and black spackles. Then the vinyl paper was applied to the global area of interest on the panel. Finally the vinyl paper was removed from the local area of interest.

To determine the geometry of the test specimen just prior to testing, an image of the unloaded specimen is taken as the reference. The specimen shape is determined by the analysis software from the image, and a best fit plane is fit to the image data using 8,000 to 10,000 data points. The best-fit plane is then used as the $\mathrm{x}$-y plane of a new coordinate system, and the data can be plotted as a three-dimensional color-coded contour plot, which permits visual identification of defects.

The VIC-3D analysis software converts the image data taken during a test to the full field $\mathrm{u}, \mathrm{v}$, and $\mathrm{w}$ displacements. Since the displacements are known, the strains can also be computed. The results can be displayed as displacement or strain contours in 2D or 3-D projections on the deformed or reference surface. Two-dimensional contour plots can also be developed. Options exist that allow extraction of displacement and/or strain results at a point in the image or along a line on the image. Selecting a line on the surface will give the profile of the panel cross-section or all displacements and strains at a pre-selected load. The line location is approximated by selecting two points on the screen. At the present it is not possible to select this line location or any point in direct relation to the specimen reference frame. Selecting a point on the screen is the only method.

For test specimens that have a curvature in a single direction, this software has an option for conversion to a cylindrical coordinate system.

\section{Analysis}

Finite element analysis of the panels was conducted using STAGS nonlinear analysis code ${ }^{6}$ to determine the test specimen response. STAGS (STructural Analysis of General Shells) is a general-purpose finite element analysis code for the analysis of shell structures of arbitrary shape and complexity. The STAGS finite element code has unique capabilities related to postbuckling analysis, crack bulging, and damage progression for metallic and laminated composite structures. STAGS also includes a progressive failure capability for laminated composite structures that is based on a point-stress analysis, traditional failure criteria, and ply discounting for material degradation. For the analysis of these panels the maximum strain failure criteria was used at the ply level. Details of the analysis of each panel configuration are given in the following sections.

\footnotetext{
${ }^{\dagger}$ VIC-3D system supplied by Correlated Solutions, Inc., W. Columbia, SC
} 


\section{A. Horizontal cut panel}

The STAGS finite element model for the Horizontal cut panels is shown in Fig. 5. The model contains 12,771 quad elements (element 410 in the STAGS element library) and 12,494 nodes. A progressive failure analysis of the Horizontal cut panel was performed with the STAGS finite element model by applying an incremental axial displacement to load the specimen to simulate the loading in a test machine. The material properties used in the analysis are typical IM6/3501 carbon-epoxy properties and are shown in Table 1. The material property values shown in Table 1 are typical vendor supplied data and the property distributions were unknown. It was necessary to estimate some of the properties not available in the literature. The predicted initial failure occurred at a load of $\mathrm{N}_{\mathrm{y}}=$ 4.84 kips/in. The initial failure, shown in Fig. 6, started at each end of the machined slot and started to turn to the right in the top detail and to the left in the bottom detail. The elements that failed indicate that 30 percent to 80 percent of the plies have failed. Increasing the axial displacement until a maximum load was achieved resulted in the predicted failure load for the specimen to be $\mathrm{N}_{\mathrm{y}}=7.87 \mathrm{kips} / \mathrm{in}$. The progression of failure to the maximum load is shown in Fig. 7. The predicted failure progressed from the initial failure down across the skin at a $35^{\circ}$ angle to the panel centerline and stops at the edge of the skin. More than $60 \%$ of the plies have failed in the elements that indicated failure. The predicted failure progressed up at a $35^{\circ}$ angle to the centerline and has turned into the transition to the stringer pad up. The predicted in-plane (v) and out-of-plane displacements (w) at the maximum load are shown in Fig. 8. The out-of-plane displacements (Fig. 8) predict a skewed pattern resulting from the anisotropic properties of the skin. An increased area of out-of-plane displacement is predicted at the skin failure area. The slot in the central stringer and skin combined with the skin fractures eliminate most of the in-plane coupling. By increasing the axial displacement, the resulting load carrying capacity of the specimen is reduced and the failure line can be predicted. After approximately 100 displacements steps, the failure progresses across one stringer as shown in Fig. 9 and the load carrying capacity is reduced to $\mathrm{N}_{\mathrm{y}}=5.78 \mathrm{kips} / \mathrm{in}$. As indicated in Fig. 9 , the stringer is predicted to be completely severed. Increasing the displacement steps completes the failure line across the entire panel as shown Fig.10 and the load capacity has fallen to $\mathrm{N}_{\mathrm{y}}=2.74 \mathrm{kips} / \mathrm{in}$. The predicted panel end shortening and transverse in-plane displacement as a function of load are shown in Fig.11. A least squares best fit to the axial displacement between 0 and $5 \mathrm{kips} / \mathrm{in}$. of load is also shown as a dashed line in Fig. 11. The slope of the line is $111.92 \mathrm{kips} / \mathrm{in} / \mathrm{in}$. At an applied load of $4.84 \mathrm{kips} / \mathrm{in}$. the predicted in-plane displacement is 15.8 percent of the axial displacement. The axial displacement curve is linear until over 5 kips/in (past the initial failure) and then slightly nonlinear to failure. The remainder of the curve reflects the load reduction indicated previously as different elements of the panel fail.

\section{B. Inclined cut panel}

The STAGS finite element model of the specimen with the inclined cut is shown in Figure 12. This model contains 12,702 quad elements and 12,429 nodes. A progressive failure analysis of the Inclined cut panel was performed with the STAGS finite element model by applying an incremental axial displacement to load the specimen to simulate the loading in a test machine. The material properties used in the analysis are typical IM6/3501 carbon-epoxy properties and are shown in Table 1 . The predicted initial failure occurred at $\mathrm{N}_{\mathrm{y}}=3.8$ kips/in. as shown in Fig. 13 and started at each end of the slot. The failed element at the bottom of the slot as shown in Fig. 13 indicated approximately 25 percent of the plies had failed while the failed element at the top of the slot indicated approximately 40 percent of the plies had failed. Increasing the axial displacement until a maximum load was achieved resulted in the predicted failure load for the specimen to be $\mathrm{N}_{\mathrm{y}}=8.53 \mathrm{kips} / \mathrm{in}$. The failure progressed down and to the left at a $50^{\circ}$ angle from the panel centerline with increasing load as shown in Fig. 14. The failure progressed into the edge of the transition area on the lower side of Fig. 14 while only a few elements indicate damage on the upper side of the slot. Information shown in Figures 14 and 15 are at a load of $\mathrm{N}_{\mathrm{y}}=8.43 \mathrm{kips} / \mathrm{in}$ which is on the unload phase after the maximum load has been achieved. The out-of-plane displacements shown in Fig. 15a predicts a positive ' $w$ ' displacement at the top end of the slot while a negative out-of-plane displacement is predicted along the lower part of the slot but not at the tip of the slot. The skin failure can be seen in the in-plane displacements (Fig. 15b). The load continues to drop as the displacement of the test machine platens is increased. The failure progresses to the edge of the panel as shown in Fig 16. At this point only the skin has failed. The stringer cap and web has not failed. A very few additional elements indicated failure at the top of the slot. Increasing the axial displacement for approximately 20 steps the load is maintained at approximately $\mathrm{N}_{\mathrm{y}}=5.7$ kips/in. Then the loads increased as the axial displacement increases resulting in more elements failing and the lower stringer failing in the web and started to fail in the cap. The predicted axial strains in the skin for $\mathrm{N}_{\mathrm{y}}=6.31$

kips/in are shown in Fig. 17. Strain in the bottom of the panel as shown in Fig. 17 is nearly zero. The fracture area is indicated by the strain in excess of 3 percent. Most of the strain is in the top of the panel where the stringer is still 
intact. The small strain concentration in the skin on the bottom of the panel is over the stringer that is not completely failed. The load reverses again with increasing the axial displacements. A few more elements fail at the upper end of the slot. Failures are occurring at other locations such as along the web and flange intersection. The predicted panel end shortening and transverse in-plane displacement as a function of load are shown in Fig.18. A least squares best fit to the axial displacement between 0 and $5 \mathrm{kips} / \mathrm{in}$. of load and has a slope of $111.2 \mathrm{kips} / \mathrm{in} / \mathrm{in}$. The axial displacement curve is linear until over 5 kips/in (past the initial failure) and then slightly nonlinear to failure. The remainder of the curve reflects the load reduction indicated previously.

\section{Test Results and Discussion}

Each panel configuration will be discussed individually in the following section

\section{Horizontal cut panels}

The profile of both Horizontal cut panels was determined using the VIC-3D system and most of the surface of panels TP-4 and TP-7 varying \pm 0.010 -inches from the theoretical plane with local areas near the edges varying up to 0.06-inch from the theoretical plane ${ }^{4}$. The Horizontal cut panels were loaded in compression until failure. The average failure load for the two Horizontal cut panels (TP-4 \& TP-7) is 7.65 kips/in. Panel TP-4 failed at 7.80 kips/in. while panel TP-7 failed at 7.51 kips/in. This average failure load of 7.65 kips is 97 percent of the predicted failure load of 7.87 kips/in. The average residual strength of the Horizontal cut panels is 37 percent of the average strength of undamaged panels ${ }^{4}$. A plot of the Horizontal cut panels axial end shortening as a function of load is shown in Figure 19 as solid lines with a filled circle (TP-4) or a filled triangle (TP-7). The transverse in-plane displacements are also shown in Fig. 19 as dashed lines and the same symbols as previously noted. The predicted end displacements are also shown in Fig. 19 as lines (solid or dashed) with a filled square symbol. The average panel axial stiffness of $100.2 \mathrm{kips} / \mathrm{in} / \mathrm{in}$. is approximately 10 percent below the computed stiffness of 111.9 kips/in./in. Specimen TP-4 transverse in-plane displacement matches the analysis predictions until a step in the displacement at approximately $5.5 \mathrm{kips} / \mathrm{in}$. The analysis predicted the in-plane transverse displacement to be 15.8 percent of axial displacement. Specimen TP-7 does not show any in-plane displacement until 5.5 kips/in.

An obvious advantage of the VIC-3D system is the recording of events at timed intervals through out the test is that phenomena that occur temporarily have a good chance of being recorded. An intermediate result from the VIC3D system is shown in Fig. 20 for panel TP-7 where the global view indicates that the panel is bulging in the middle as determined by the concentric out-of-plane contours around the slot. These Horizontal cut panels also had a second VIC-3D system recording the response at a local area as defined at the left end of the slot as shown in Fig. 20. This local area, shown in Fig. 20, indicated a delamination was in progress at the corner of the slot for panel TP7. The delamination shown is for a load of $\mathrm{N}_{\mathrm{y}}=5.1 \mathrm{kips} / \mathrm{in}$. and is near the end of the slot. The appearance of the delamination started at approximately $\mathrm{N}_{\mathrm{y}}=4.6 \mathrm{kips} / \mathrm{in}$. and continued to grow until $\mathrm{N}_{\mathrm{y}}=5.61 \mathrm{kips} / \mathrm{in}$. The delamination could have started at a lower load but would be missed due to a strip of image data on all edges that is lost in the analysis process. There could also have been a delamination on the right end of the slot as it was not be monitored with a local set of cameras. Up to a load of $\mathrm{N}_{\mathrm{y}}=5.61 \mathrm{kips} / \mathrm{in}$ the delamination was only visible in the local area images. At $\mathrm{N}_{\mathrm{y}}=5.76 \mathrm{kips} / \mathrm{in}$ the delaminations/damage grew in size and was visible in the global view image on the L/H side of the slot as shown in Fig. 21a and the delamination/damage does not appear on the R/H side of the slot until $\mathrm{N}_{\mathrm{y}}=5.82 \mathrm{kips} / \mathrm{in}$. as shown in Fig. 21b. Increasing the axial displacement until failure the damage progresses up and to the left and down and to the right as shown in Fig. 22, which is the last image frame before failure. The damage progressed to the edge of the skin, adjacent to the thickness transition to the stiffener padup as shown in Fig. 22. This damage/delamination growth compares well with the predicted damage growth shown in Fig. 7 where the damage grew to the stiffeners at reaching the maximum load. Panel TP-4 did not exhibit the local delamination as was seen in panel TP-7. Panel TP-4 appeared to fail in the skin from the corner of the slot to the edge of the skin as shown Fig. 23. The first appearance of any out-of-plane displacement in the local images is shown in Fig 23a. At the same time the out-of-plane displacements appeared in the global image as shown in Fig. 23b indicating failure from the end of the slot to the edge of the skin. Panel TP-4 reacts the same as TP-7 and the progressive failure analysis predictions that of the skin failing to the stiffeners as the load increases to the maximum load. Increasing the load resulted in the damage to grow into the padup area of the stringer on the right hand side as shown in Fig. 24.

As indicated previously in this paper, strain can be computed from the $\mathrm{u}, \mathrm{v}$, and $\mathrm{w}$ displacements determined from the VIC-3D images. The axial strain $\left(\varepsilon_{\mathrm{yy}}\right)$ profile for the panel TP-4 image area, which covers approximately $60 \%$ of the skin surface is shown in Fig. 25a for an applied load of $N_{y}=5.6$ kips/in. which is the load just prior to 
initial failure. This load was selected to have a flat surface to compute the strain in lieu of a load after initial failure where the surface is not flat due to the outer layers delaminating and buckling away from the surface. A non-flat surface would not allow a good strain computation. The anisotropic skin appears to have an effect on the shape of the strain contours at the end of the slot. Two points located at 0.38-inches and 1.0-inches from the left end of the slot have been selected to determine the strain as a function of load. The strain, at these selected points, has been extracted from the VIC-3D images and is shown in Fig. 25b. Strains from gages 28 and 34 which are on the opposite side to the selected points on panel TP-4 are also shown in Fig. 25b. The VIC-3D strain, shown in Fig. 25b, from the point at 0.38 -inches from the slot would not be reliable above the load of $\mathrm{N}_{\mathrm{y}}=5.6 \mathrm{kips} / \mathrm{in}$ due to the delamination and buckling from the initial failure. The strain at the point at 1.0-inch from the slot would be more reliable since this location is on the edge of the buckled lamina. There is a good correlation between the strains up to a load of 5.6 kips/in. Strain results from panel TP-7 are shown in Fig. 26 which is plotted to the same scale as Fig. 25. Comparing the Fig. 25 and Fig. 26 indicates that the response of panel TP-7 is similar to the response of panel TP-4. The predicted axial strains $\left(\varepsilon_{\mathrm{yy}}\right)$ contours for the Horizontal cut panels is shown in Fig. 27 for an applied load of 5.58 kips/in. Comparing Figures 27, 26 and 25 the following can observed: a) all figures have an area through the center of the panel of near zero axial strain, b) the shape of the strain distributions at the end of the slots are very similar, c) the magnitude of the strains along the side of the panels are similar.

A photograph of the stringer side of a failed Horizontal cut specimen is shown in Figure 28a. As indicated in the figure, the failure progressed from each end of the slot up or down across the skin. A view of the skin side of the specimen is shown in Figure 28b. This figure indicates how the failure progressed from the right end of the slot down at approximately a $35^{\circ}$ angle until it intersected the stringer then turned and crossed perpendicular to the stringer. Likewise, failure started at the left end of the slot and progressed up at approximately $35^{\circ}$ until it approached the stringer, the damage turned parallel to the stringer for a short distance, then turned and crossed perpendicular to the stringer. The progressive failure analysis noted earlier, predicted that the failures would be at $35^{\circ}$ to the specimen centerline then turn and cross perpendicular to the stringer which is a very good match with the experimental results. Both of the Horizontal cut panels (TP-4 and TP-7) failed in a similar manner and indicates that the fabrication sequence did not contribute to the failure where the panels were manufactured at different times.

In summary, the results shown for the Horizontal cut panels indicate a very good correlation between the predicted failure mode and actual failure mode. The predicted failure load of $7.87 \mathrm{kips} / \mathrm{in}$. was less than 3\% higher than the average failure load of the two Horizontal cut specimens. The average panel stiffness is approximately 90 $\%$ of the computed panel stiffness. This is a good strength and stiffness correlation since the exact properties of the material used in the panel was unknown.

\section{Inclined cut panel}

The profile of the Inclined cut panel (Fig. 4) indicates that the panel is curved across the panel width as shown in Fig. 29. The panel curvature varies up to 0.025 -inches from being flat between the stringers and curves to 0.050inches from the reference plane between the stringers and panel edges. There is no noticeable curvature in the lengthwise direction. The local area can be seen in Fig. 29 and is where a second VIC-3D system recorded the images of a small area at the end of the slot. The 0.004-inch step can be observed around the edge of the local area in Fig. 29. A defect of unknown origin, shown in Fig. 29, could be an air bubble trapped under the vinyl or a foreign object under the vinyl. The ripple in the contours as shown in Fig. 29 indicates the edge of the painted area under the vinyl for the local area images. The error (noise) in the results can be determined from the VIC-3D analysis and is less than 0.0003-inch for the Inclined cut panel. The panel was loaded in compression until failure occurred at 7.54 kips/in. The residual strength of the Inclined cut panel is 37 percent of the average strength of the undamaged panels ${ }^{4}$. A plot of the axial end shortening as a function of the axial load is shown in Fig. 30 as a solid line with a filled circle symbol. The transverse in-plane displacements are also shown in Fig. 30 as dashed lines with a filled circle symbol. The panel end shortening shown in Fig. 30 is a uniform function of the load until 6.1 kips/in. where the slope of the curve changes due to a local failure. The initial specimen stiffness is $103.6 \mathrm{kips} / \mathrm{in} / \mathrm{in}^{4}$. The predicted panel end shortening and in-plane displacement is also shown in Fig. 30 as lines (solid and dashed) with a filled square symbol. The predicted panel end shortening is a linear function of the applied load until a load of 6.6 kips/in. The predicted stiffness of the panel is $111.2 \mathrm{kips} / \mathrm{in} / \mathrm{in}$.

An intermediate result from the VIC-3D system at $\mathrm{N}_{\mathrm{y}}=6.32 \mathrm{kips} / \mathrm{in}$ is shown in Fig. 31 and indicates that the panel is bulging as indicated by the concentric displacement contours around the slot. This out-of-plane deflections is different from the predicted displacement shown in Fig. 15 where one end of the slot deflects in one direction with the opposite slot end deflecting in the opposite direction. The local area image indicates a delamination at the corner of the slot. The delamination shown in Fig. 31 first appeared at $\mathrm{N}_{\mathrm{y}}=5.32 \mathrm{kips} / \mathrm{in}$. and increased in size until $\mathrm{N}_{\mathrm{y}}=$ 6.32 kips/in. Damage started to show up in both ends of the slot as shown in Fig. 32 after a very small perturbation 
in the load. Increasing the axial displacement resulted in the damage progressing to and into the stiffeners as shown in Fig. 33 which is the last image before panel failure. Comparing Fig. 33 with the predicted failure direction shown in Fig. 14 indicates the failure direction is the same, down to the right for one end of the slot.

The VIC-3D axial strain $\left(\varepsilon_{\mathrm{yy}}\right)$ profile for the Inclined cut panel is shown in Fig. 34a for $\mathrm{N}_{\mathrm{y}}=6.03 \mathrm{kips} / \mathrm{in}$. Two points located at 0.38 -inches and 1.0-inches from the left end of the slot have been selected to determine the strain as a function of load. The strains at these selected points has been extracted from the VIC-3D images and are shown in Fig. 34b. Strains from gages 28 and 34 which are on the opposite side to the selected points on the Inclined cut panel are also shown in Fig. 34b. There is good correlation between the strain gages and strain extracted from the VIC-3D images until the skin started of deflect out-of-plane or approximately $4.0 \mathrm{kips} / \mathrm{in}$. The predicted axial strains $\left(\varepsilon_{\mathrm{yy}}\right)$ contours for the Inclined cut panel is shown in Fig. 35 for an applied load of 6.07 kips/in. The anisotropic skin appears to have an effect on the shape of the strain contours at the end of the slot. Comparing Figures 34 and 35 the following can observed: a) both figures have an area through the center of the panel of near zero axial strain, b) the shape of the strain distribution at the left end of the slot is similar while the right end of the slot is different, the magnitudes of the strain along the sides of the panel are similar.

A photograph of the failed Inclined cut panel is shown in Fig. 36. As indicated in Fig. 36a the failure in the skin progressed up from the $\mathrm{L} / \mathrm{H}$ end of the slot at approximately a $50^{\circ}$ angle and then turned to cross the stringer. Failure progresses in the skin from the right hand end of the slot at a $30^{\circ}$ angle from the horizontal and then turned to cross the stringer. The progressive failure analysis predicted that failure would progress from the slot end at a $50^{\circ}$ angle to the edge of the skin and turn to cross the stringer which matches the experimental results. Failure from the opposite slot end was not predicted by the analysis.

In summary, the results shown for the Inclined cut panel indicate a very good correlation between the predicted failure mode and the actual failure mode. The failure load of $\mathrm{N}_{\mathrm{y}}=7.54 \mathrm{kips} / \mathrm{in}$ is $88 \%$ of the predicted failure load of the inclined panel and the actual stiffness is $93 \%$ of the predicted panel stiffness. This is a good strength and stiffness correlation since the actual properties of the material used in the panel was unknown.

The Horizontal cut and Inclined cut panels response while under a compression load was recorded with strain gages, displacement transducers and 3D Vision Correlation System (VIC-3D) and there was good correlation between the three methods used in the investigation. The VIC-3D method has several advantages over contemporary strain gages and displacement transducers such as being noninvasive to structure, the equipment is not damaged when structural failure occurs, and preparation time is significantly reduced. One of the main advantages that VIC-3D has over other methods is the ability to detect different events during the loading phase while recording at the global level and not at local or micro level. This means that the need to know high strain locations on the panel before attaching strain gages or displacement transducers is eliminated. The VIC-3D system allowed the tracking of damage progression to the edge of the skin as the load increased which followed the same path as predicted by the STAGS analysis.

\section{Concluding Remarks}

Progressive failure analysis has been applied to discrete damaged tailored extension-shear-coupled I-stiffened composite compression panels. The center stringer and adjacent skin on a 3-I stiffener extension-shear coupled panels was cut for the discrete damage. The panels were analyzed with STAGS finite element program using the progressive failure analysis option. The STAGS results compared very well with the experimental results in failure load, stiffness prediction and failure direction. STAGS over predicted the failure load by less than $12 \%$ and the panel stiffness by less than $10 \%$. The STAGS analysis matched the experimental failure location and direction.

The VIC-3D method used to record the panel response has several advantages over contemporary strain gauges and displacement transducers such as noninvasive to structure, equipment is not damaged when failure occurs, and preparation time is significantly reduced. One of the main features that VIC-3D has over other methods is to detect different events during the loading phase while recording at the global level.

There is a good match of the panel stiffness and strength between the progressive failure analysis and the experimental results. The results indicate that the tailored concept would be feasible to use in the wing skin of a tiltrotor aircraft. 


\section{References}

1 Popelka, D., Sheffler, M., and Bilger, J. "Correlation of Test and Analysis for the 1/5th Scale V-22 Aeroelastic Model." Journal of the American Helicopter Society, Vol 32, (2), April 1997.

2 Popelka, D., Lindsay, D., Parham, T.,Jr., Berry, V., and Baker, D., "Results of an Aeroelastic Tailoring Study for a Composite Tiltrotor Wing," Presented at the 51 ${ }^{\text {st }}$ Annual American Helicopter Society Form, Fort Worth, TX, May 1995.

3 Corso, L. M., Popelka, D. A., Nixon, M. W., "Design, Analysis, and Test of a Composite Tailored Tiltrotor Wing." Presented at the $53^{\text {rd }}$ annual American Helicopter Society Forum, Virginia Beach, VA, April 1997.

${ }^{4}$ Baker, Donald J, ”Response of Damaged and Undamaged Tailored Extension-Shear-Coupled Composite Panels,” AIAA2003-1461, presented at the $44^{\text {th }}$ Structures, Structural Dynamics, and Materials Conference, Norfolk, VA, April 7-10, 2003.

5 Helm, J. D., McNeil, S. R., Sutton, M. A., "Improved Three-Dimensional Image Correlation for Surface Displacement Measurement,” Optical Engineering, Vol. 35, No 7, July 1996, pp1911-1920.

6 Brogan, F. A., Rankin, C. C., and Cabiness, H. D., "STAGS Users Manual," Lockheed Palto Alto Research Laboratory, Report LNSC P032594, 1994.

Table 1

\begin{tabular}{|l|l|l|l|}
\hline & & Material & \\
\hline & $\begin{array}{l}\text { IM6-3501-6 } \\
\text { tape material. }\end{array}$ & $\begin{array}{l}\text { Carbon fabric } \\
\text { interlayer. }\end{array}$ & $\begin{array}{l}\text { FM 300 } \\
\text { Adhesive. }\end{array}$ \\
\hline $\mathrm{E}_{1} \times 10^{5}$ psi. & 210 & 90. & 1.32 \\
\hline $\mathrm{E}_{2} \times 10^{5}$ psi. & 120 & 85. & 1.32 \\
\hline $\mathrm{E}_{3} \times 10^{5}$ psi. & 120 & 12. & 1.32 \\
\hline $\mathrm{G}_{12} \times 10^{5}$ psi. & 8.7 & 8.0 & 1.30 \\
\hline $\mathrm{G}_{13} \times 10^{5}$ psi. & 8.7 & 4.0 & 1.30 \\
\hline $\mathrm{G}_{23} \times 10^{5}$ psi. & 2.58 & 4.0 & 1.30 \\
\hline$\mu_{12}$ & 0.3 & 0.3 & 0.3 \\
\hline$\mu_{13}$ & 0.3 & 0.3 & 0.3 \\
\hline$\mu_{23}$ & 0.3 & 0.3 & 0.3 \\
\hline $\mathrm{X}_{\mathrm{c}}$, psi. & $190,000$. & $70,000$. & $10,000$. \\
\hline $\mathrm{X}_{\mathrm{t}}$, psi. & $232,750$. & $110,000$. & $7,000$. \\
\hline $\mathrm{Y}_{\mathrm{c}}$, psi. & 28,700 & $70,000$. & $10,000$. \\
\hline $\mathrm{Y}_{\mathrm{t}}$, psi. & $14,700$. & $100,000$. & $7,000$. \\
\hline $\mathrm{S}_{\mathrm{xy}}$, psi. & $29,750$. & $13,000$. & $7,000$. \\
\hline $\mathrm{Z}_{\mathrm{c}}$, psi. & $28,700$. & $28,700$. & $10,000$. \\
\hline $\mathrm{Z}_{\mathrm{t}}$, psi. & $14,700$. & $14,700$. & $7,000$. \\
\hline $\mathrm{S}_{\mathrm{yz}}$, psi. & $29,750$. & $13,000$. & $7,000$. \\
\hline $\mathrm{S}_{\mathrm{xz}}$, psi. & $29,750$. & $13,000$. & $7,000$. \\
\hline
\end{tabular}



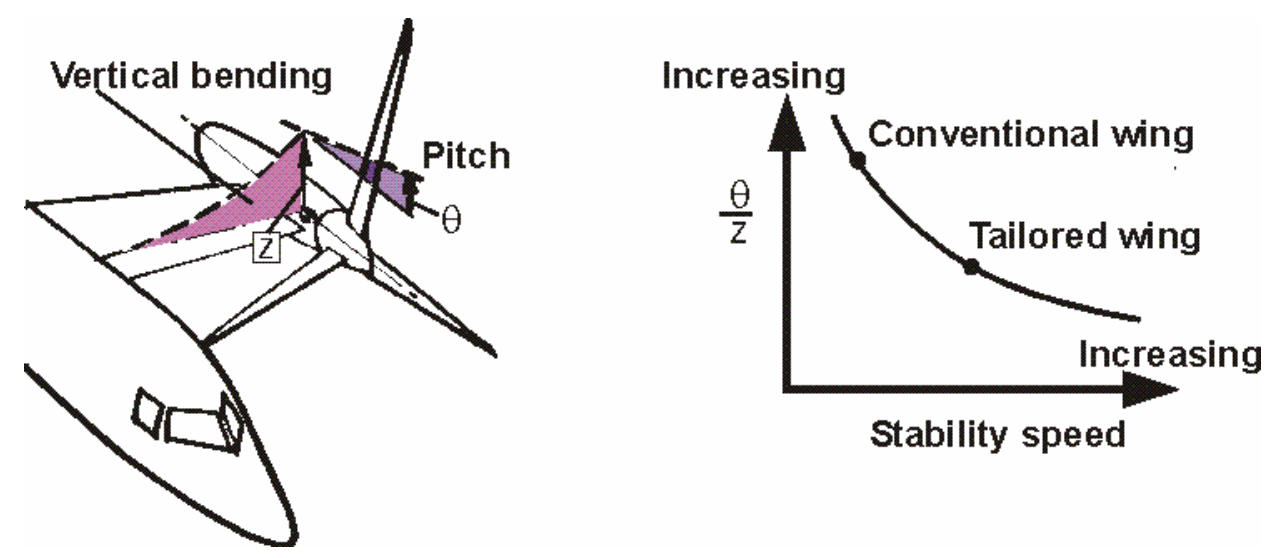

Figure 1. Influence of structural tailoring on wing aeroelastic stability.

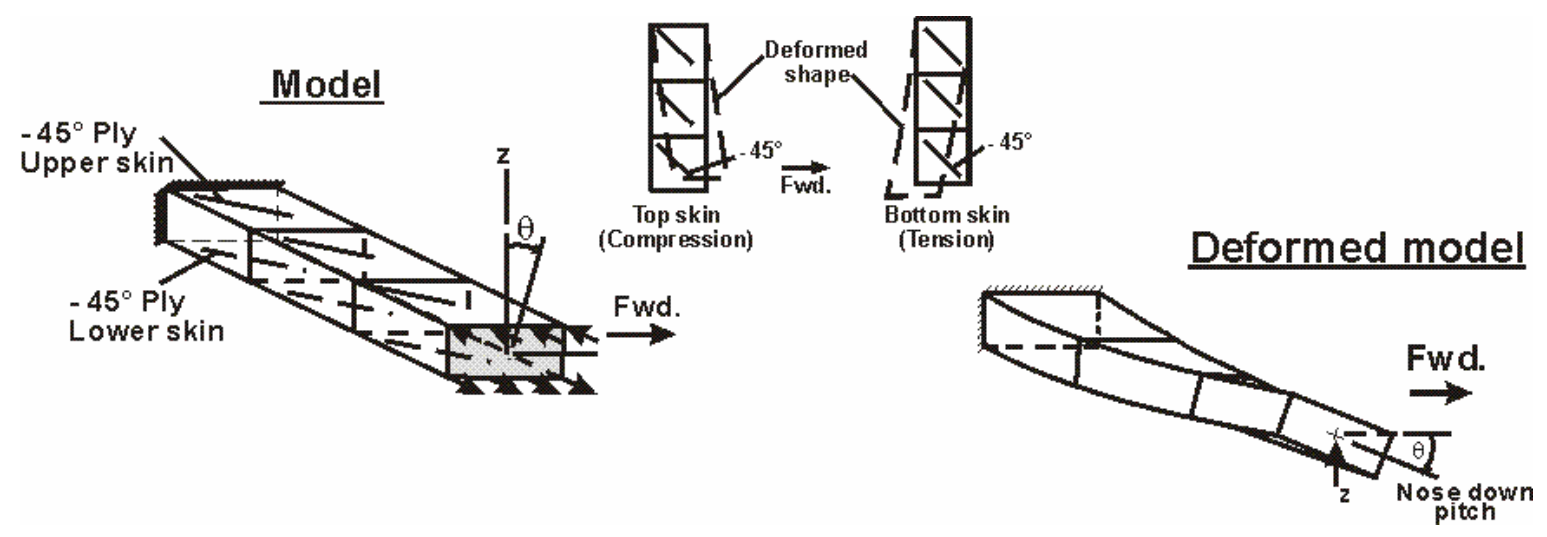

Figure 2. Simple boxbeam model.

\section{As fabricated panel}

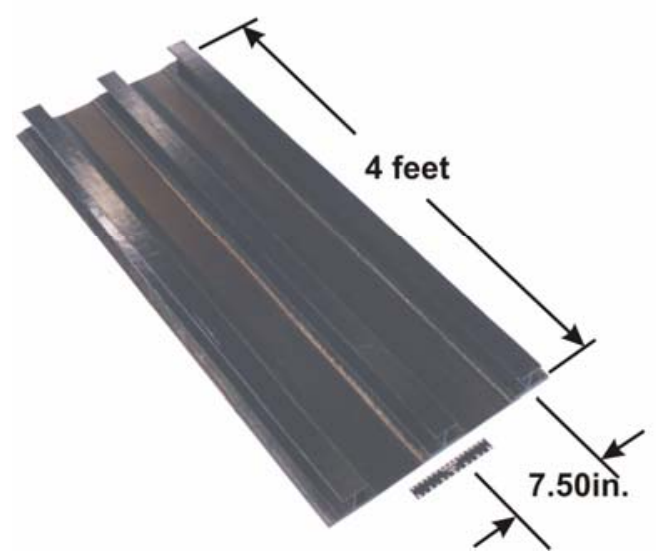

Typical panel cross-section at stiffener.

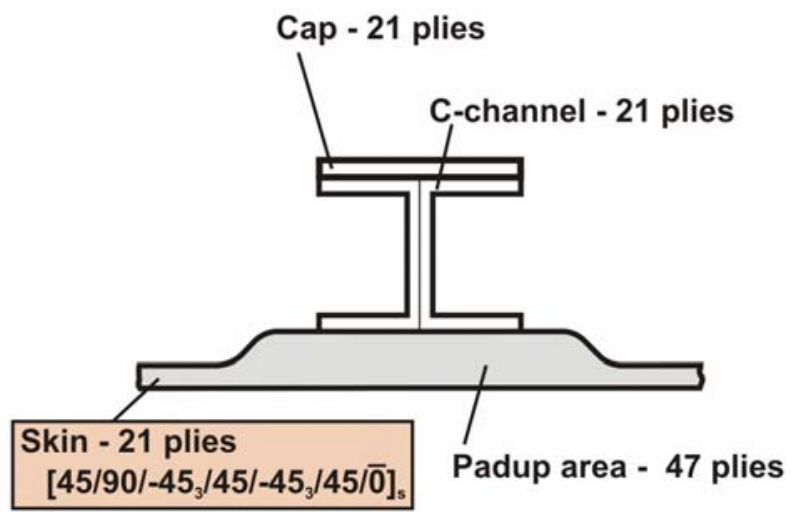

Figure 3. Specimen configuration 
Horizontal cut

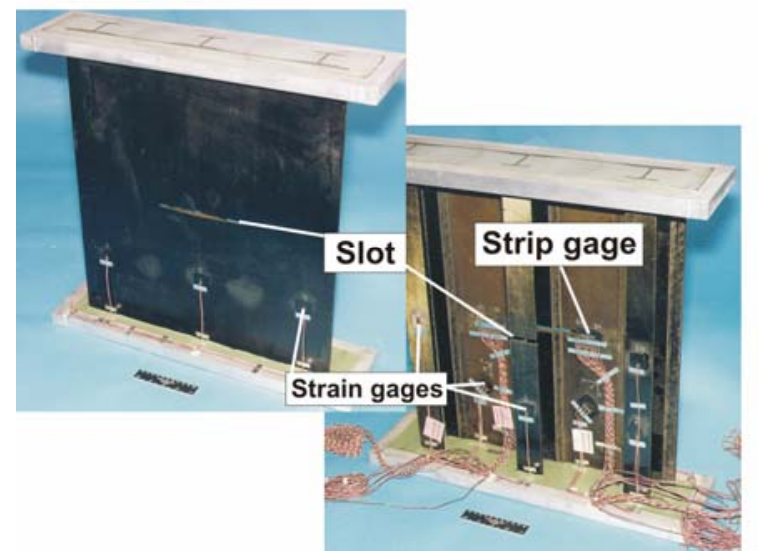

Inclined cut

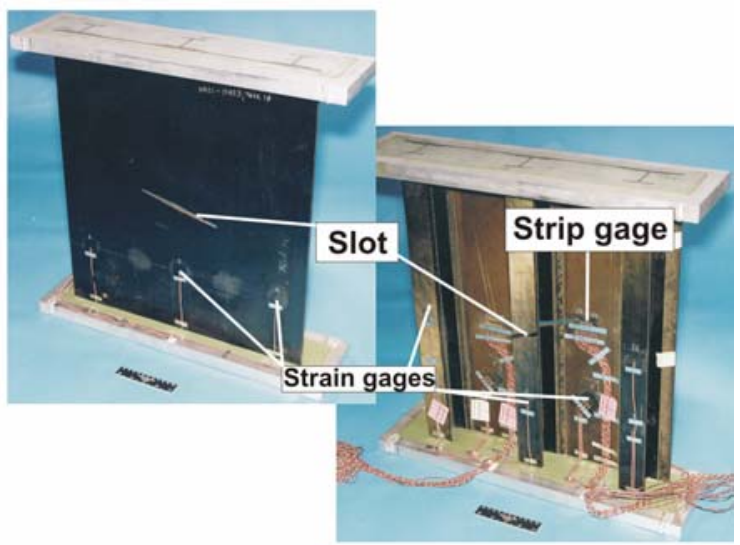

Figure 4. Horizontal cut and Inclined cut test panels.

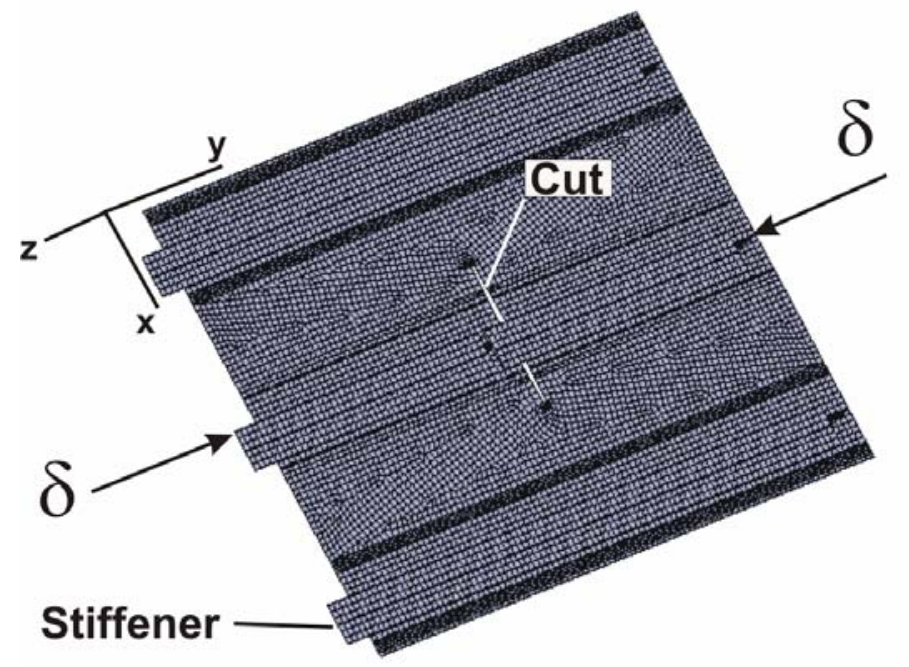

Figure 5. Finite element model of Horizontal cut panel.
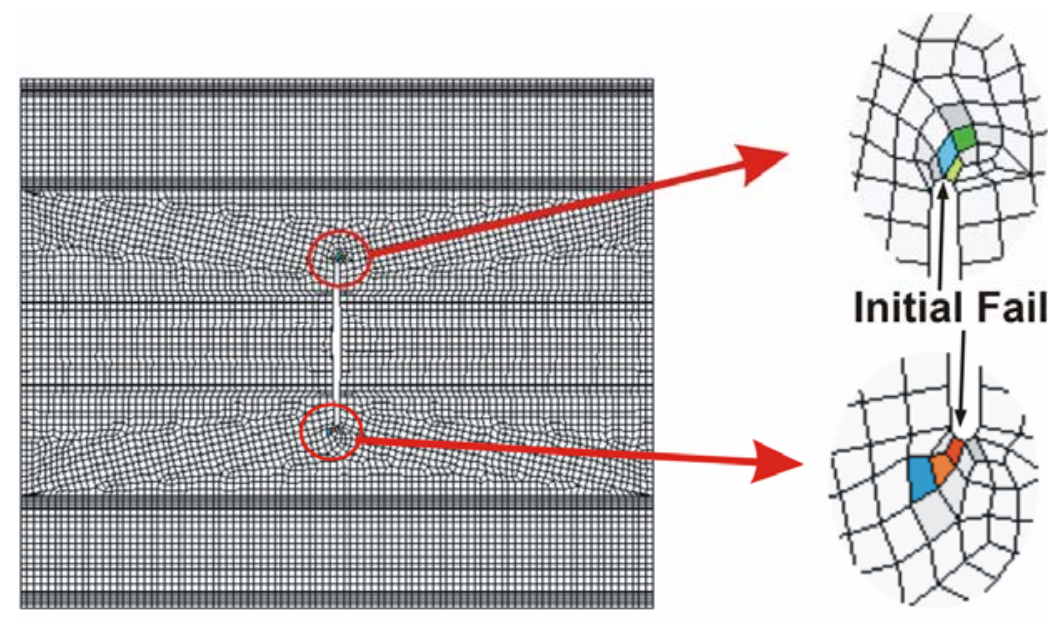

Ply Failure, \%
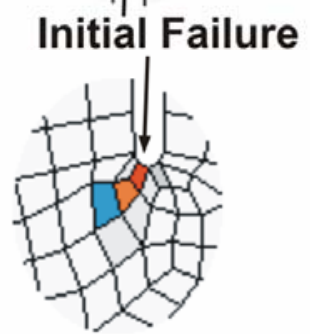

50

Figure 6. Initial failure in Horizontal cut panel, $N_{y}=4.84$ kips/in. 


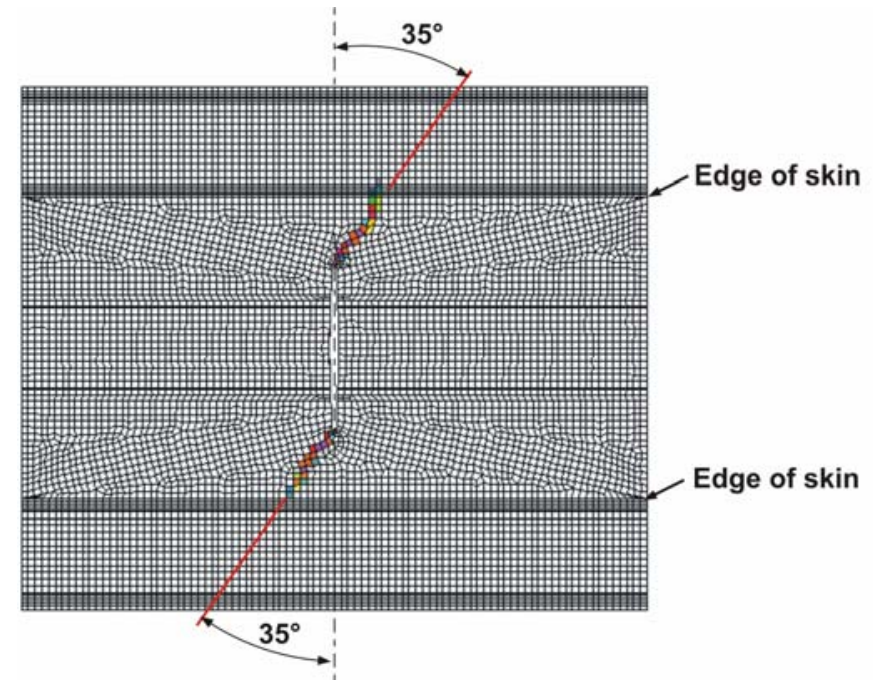

Ply Failure, \%

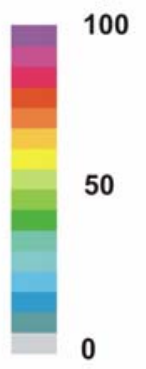

Figure 7. Predicted failure in Horizontal cut panel at maximum load, $N_{y}=7.87$ kips/in.

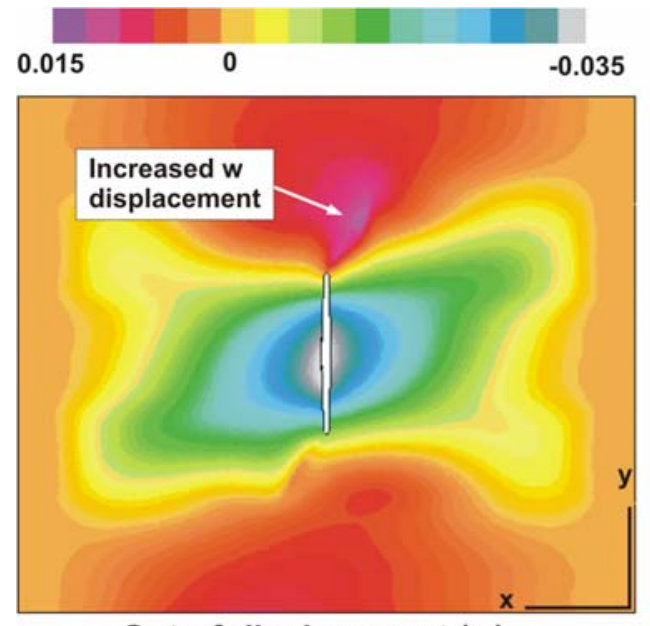

Out-of-displacement (w)
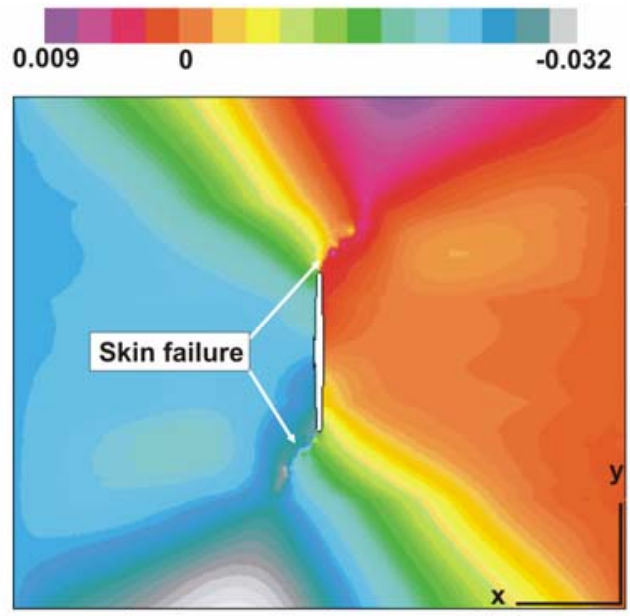

In-plane displacement (v)

Figure 8. Predicted in-plane and out-of-plane displacements in Horizontal cut panel at $\mathbf{N}_{\mathbf{y}}=7.87$

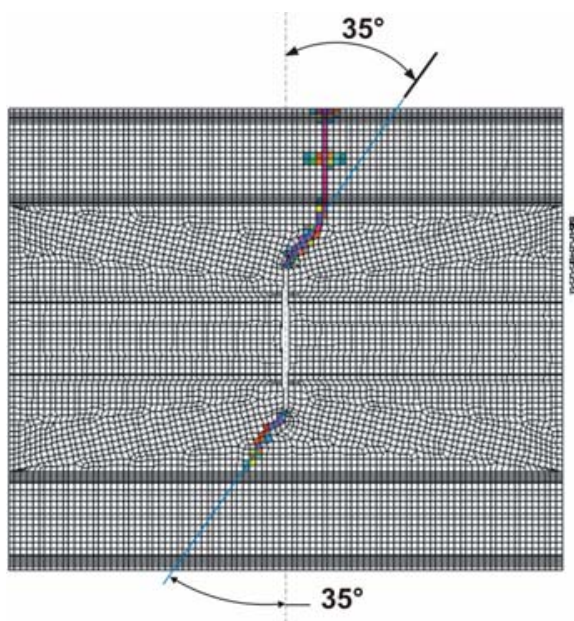

Ply Failure, \%

\section{Failure across stringer cap}
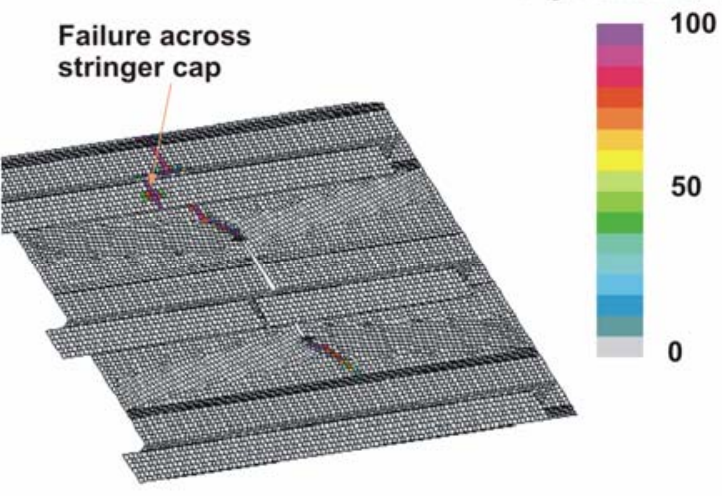

50

Figure 9. Predicted failure path in Horizontal cut panel at $\mathrm{N}_{\mathrm{y}}=5.78 \mathrm{kips} / \mathrm{in}$. 

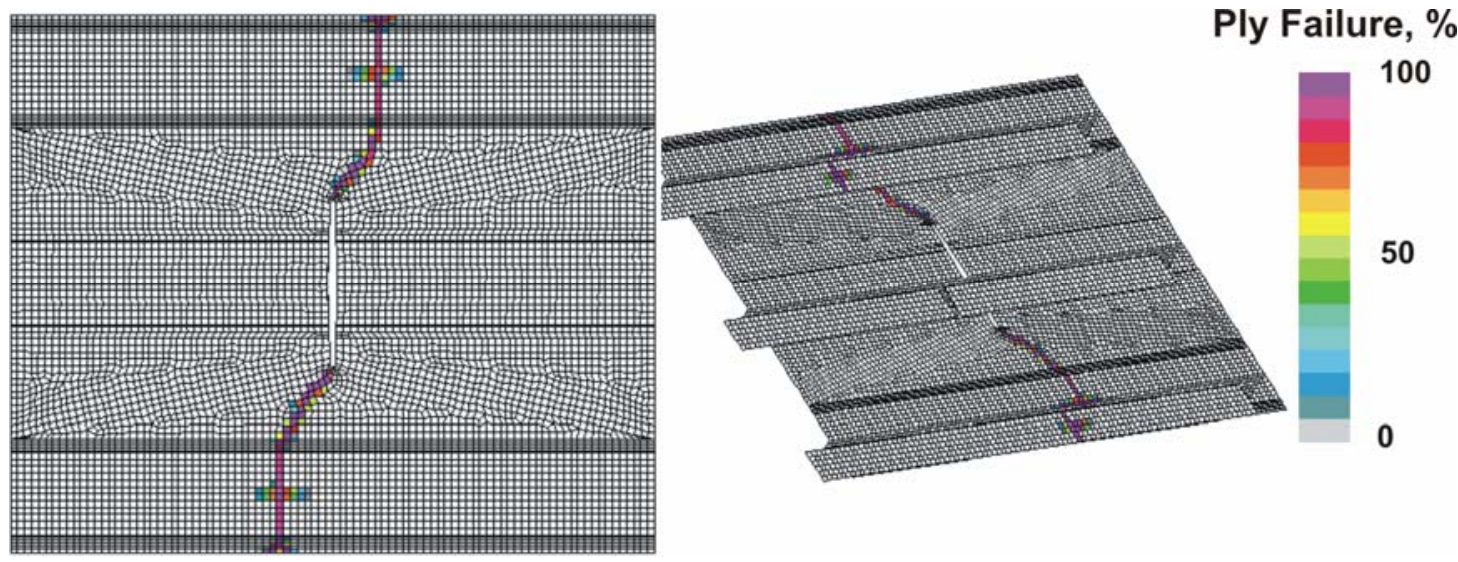

Figure 10. Predicted panel failure in Horizontal cut panel at $\mathrm{Ny}=2.74 \mathrm{kips} / \mathrm{in}$.
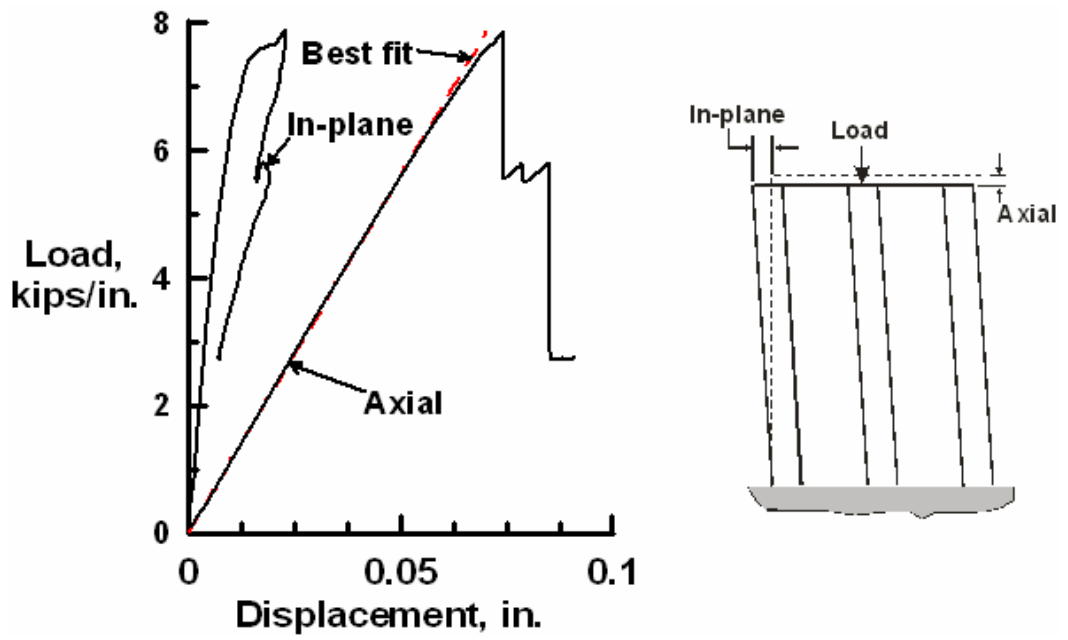

Figure 11. Predicted axial and transverse in-plane displacements in Horizontal cut panel as a function of load.

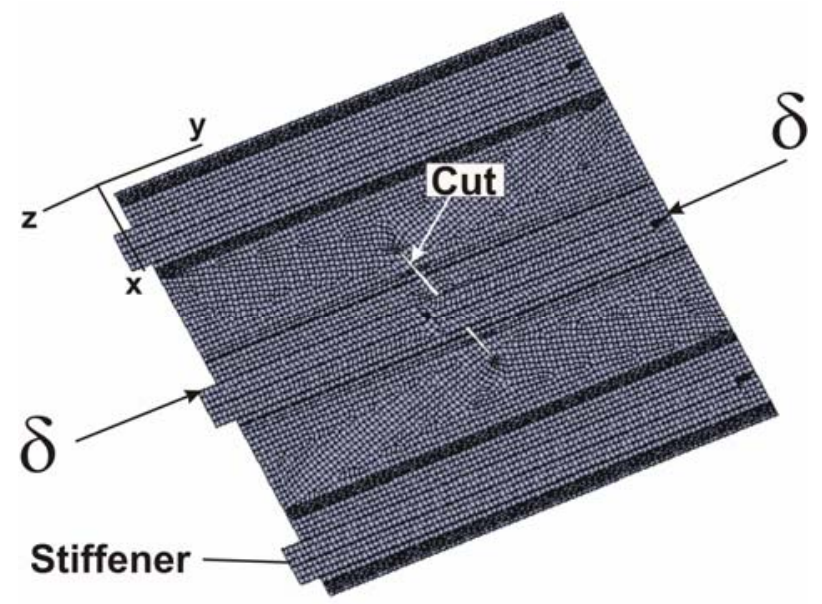

Figure 12. Finite element model of Inclined cut panel. 


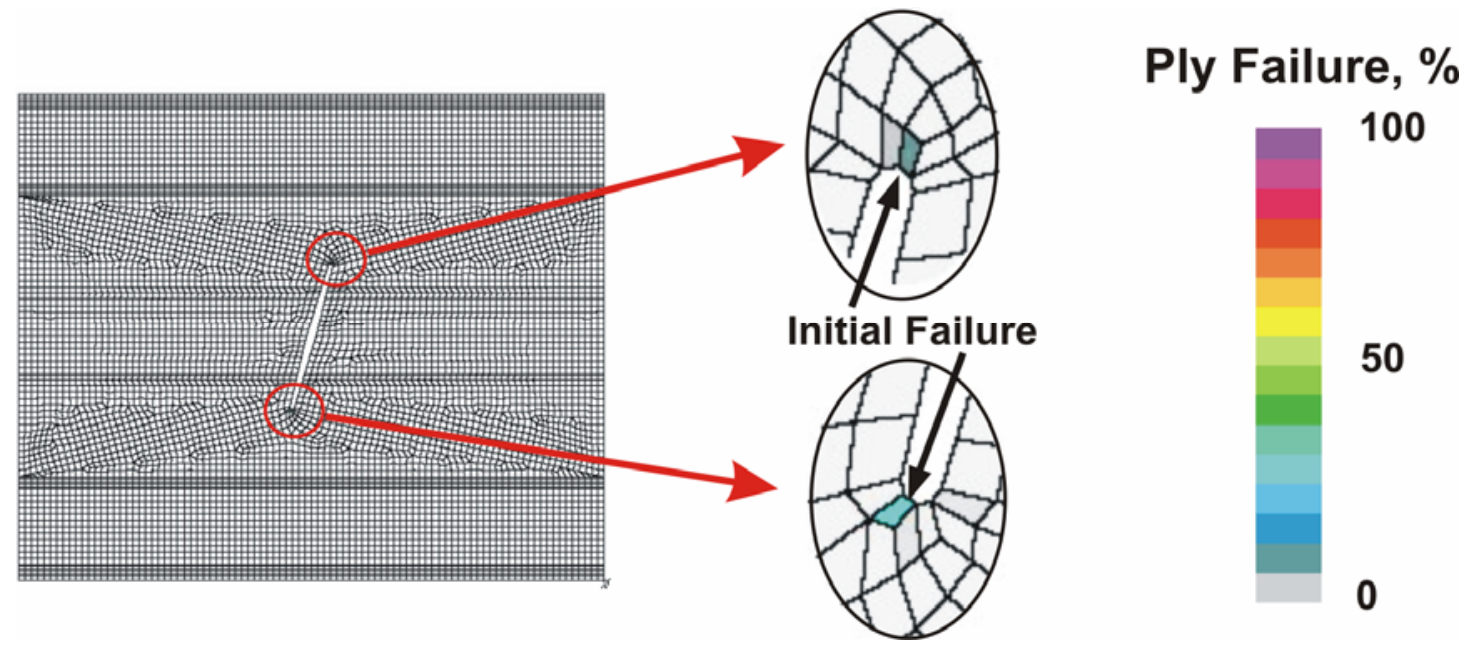

Figure 13. Predicted initial failure in the Inclined cut panel, $\mathrm{N}_{\mathrm{y}}=3.8 \mathrm{kips} / \mathrm{in}$.

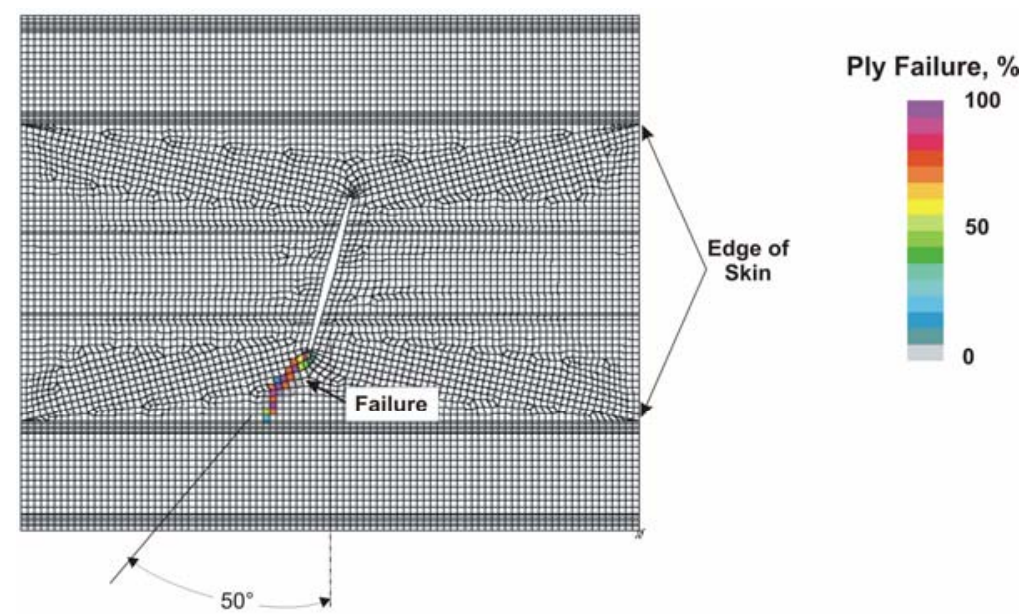

Figure 14. Predicted failure in Inclined cut panel $\mathrm{N}_{\mathrm{y}}=8.43 \mathrm{kips} / \mathrm{in}$.

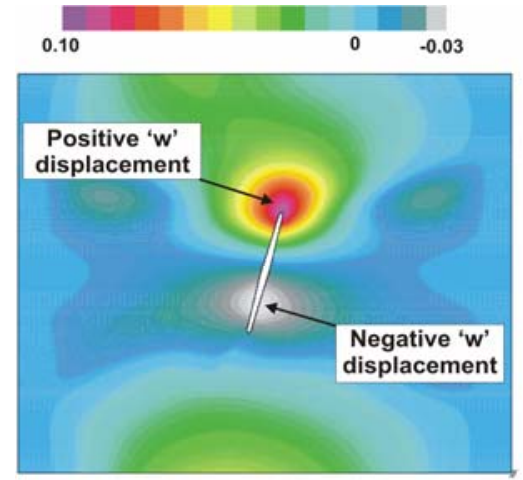

a. Out-of-displacement (w)

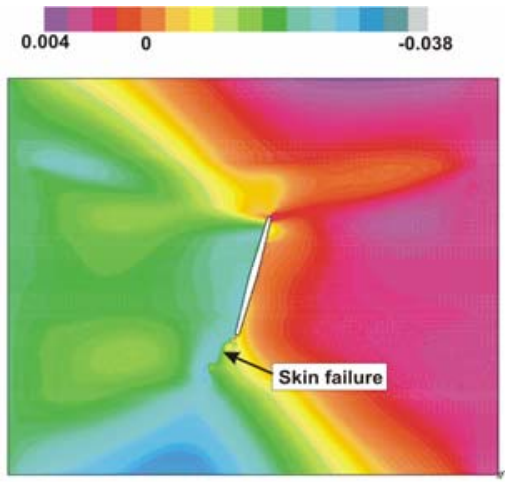

b. In-plane displacement (v)

Figure 15. Predicted in-plane and out-of-plane displacements in Inclined cut panel, $\mathrm{N}_{\mathbf{y}}=\mathbf{8 . 4 3}$ kips/in. 


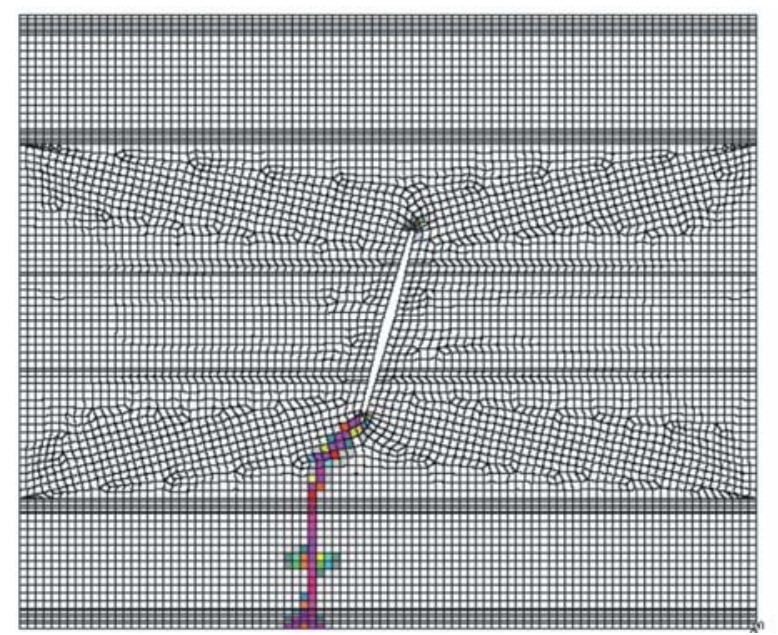

Ply Failure, \%

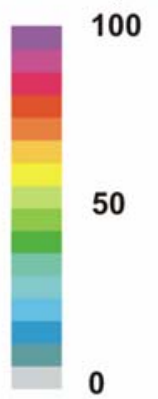

Figure 16. Progression of failure in Inclined cut panel at $\mathrm{N}_{\mathrm{y}}=5.69 \mathrm{kips} / \mathrm{in}$.
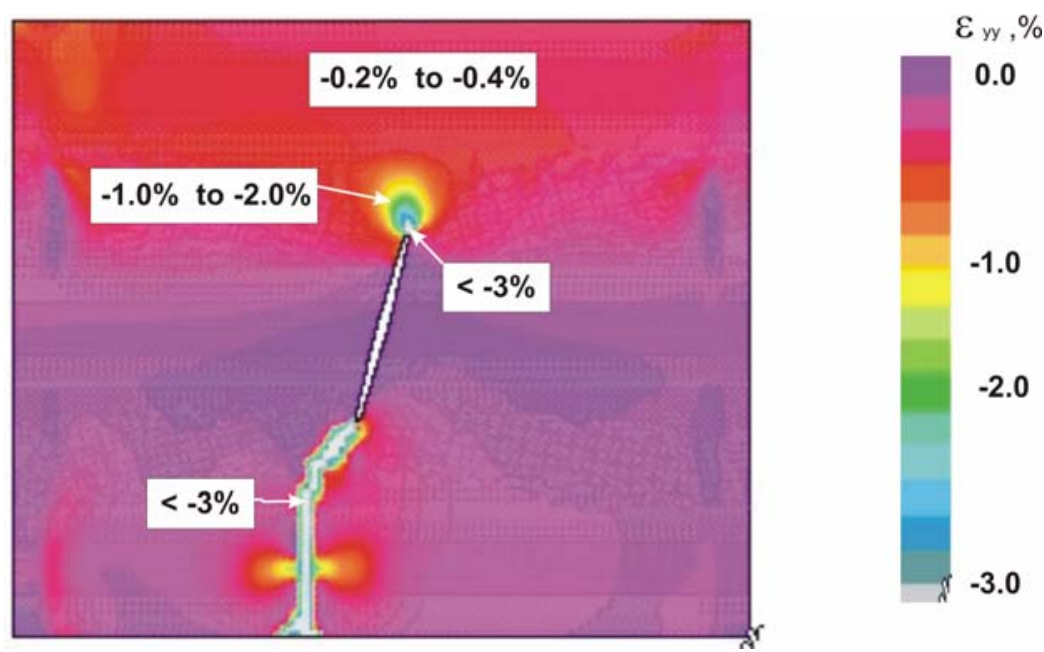

Figure 17. Predicted axial strains in the skin of Inclined cut panel at $\mathrm{N}_{\mathrm{y}}=6.31 \mathrm{kips} / \mathrm{in}$.
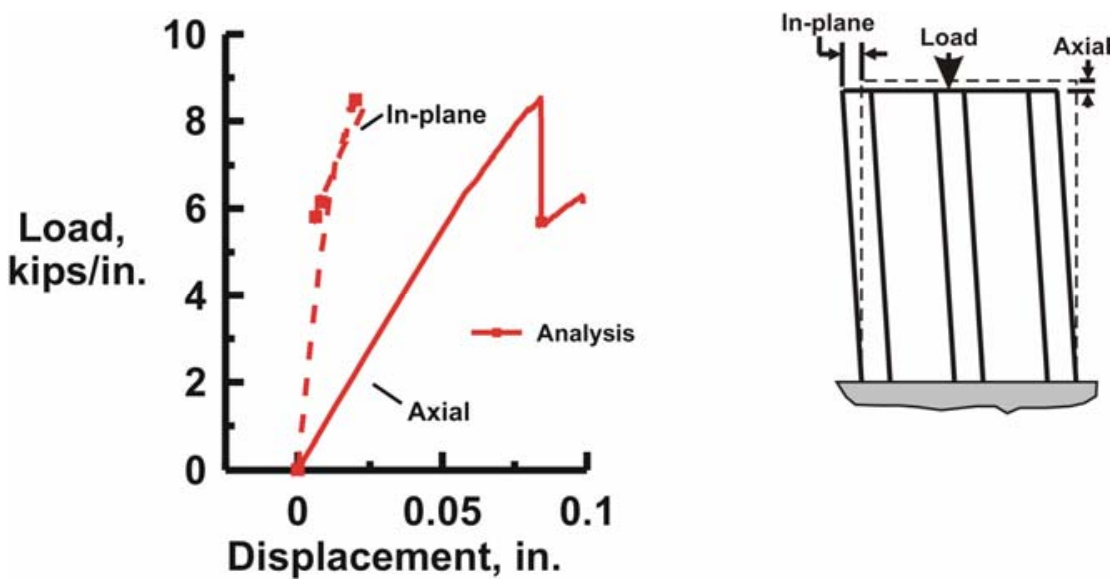

Figure 18. Predicted axial and transverse in-plane displacements as a function of load for the Inclined cut panel. 


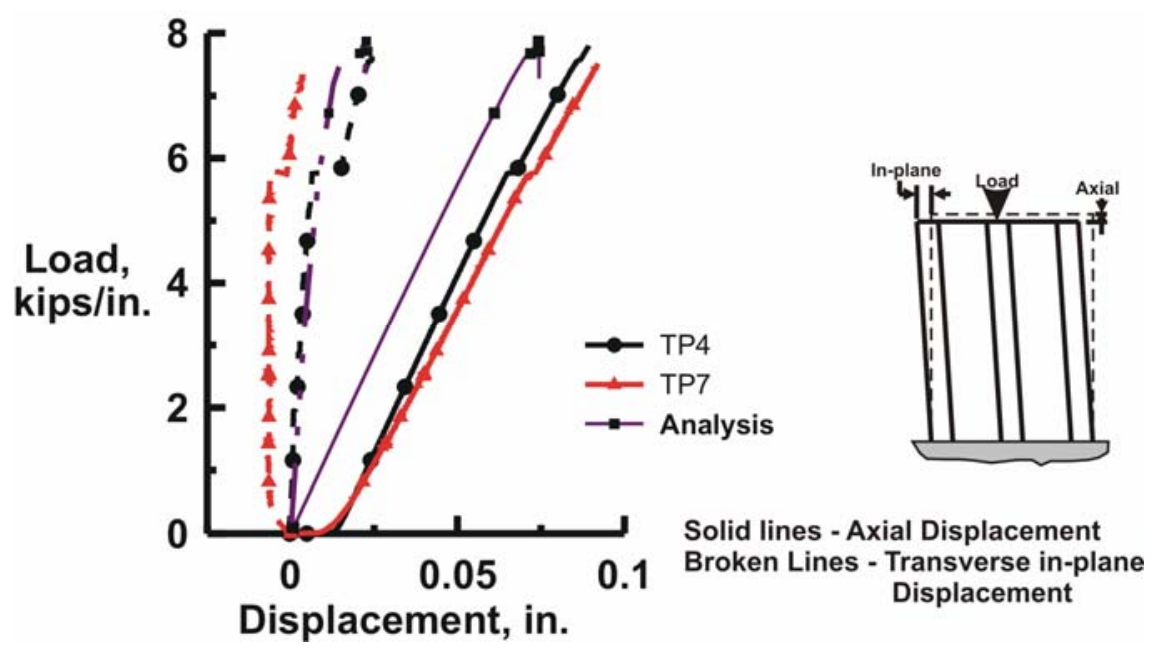

Figure 19. Axial and transverse in-plane displacements as a function of applied load.

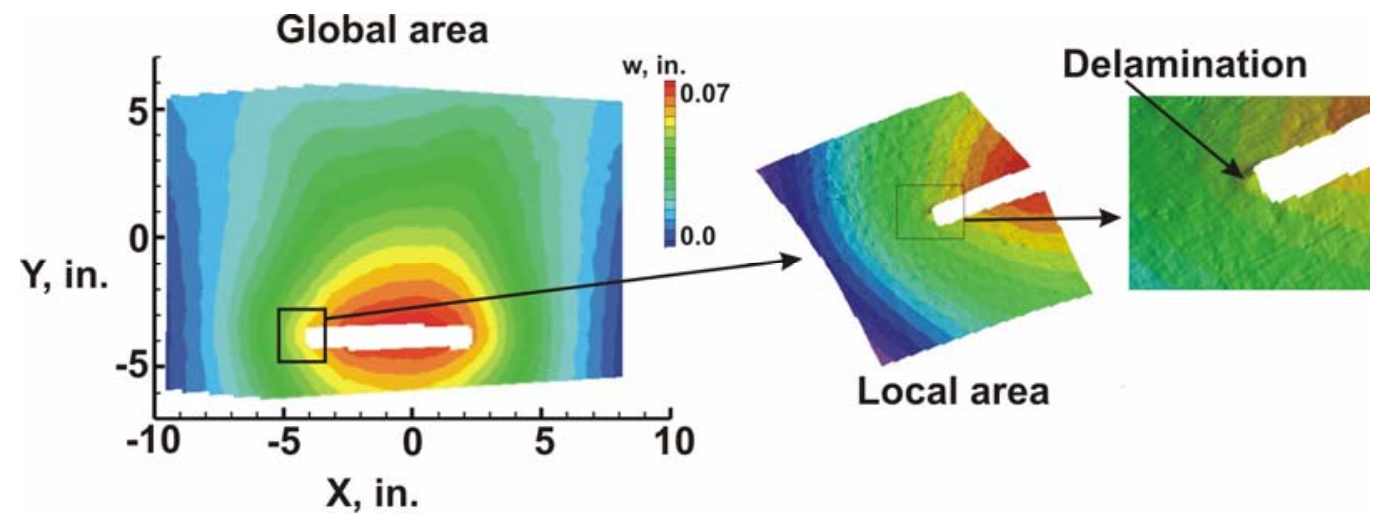

Figure 20. Measured delamination at end of slot in panel TP-7 at a load of $\mathrm{Ny}=5.1 \mathrm{kips} / \mathrm{in}$.

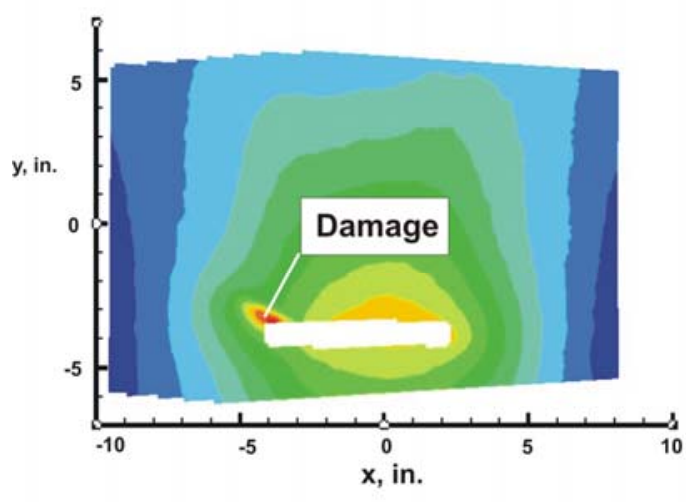

a. $\mathrm{Ny}=5.76 \mathrm{kips} / \mathrm{in}$.

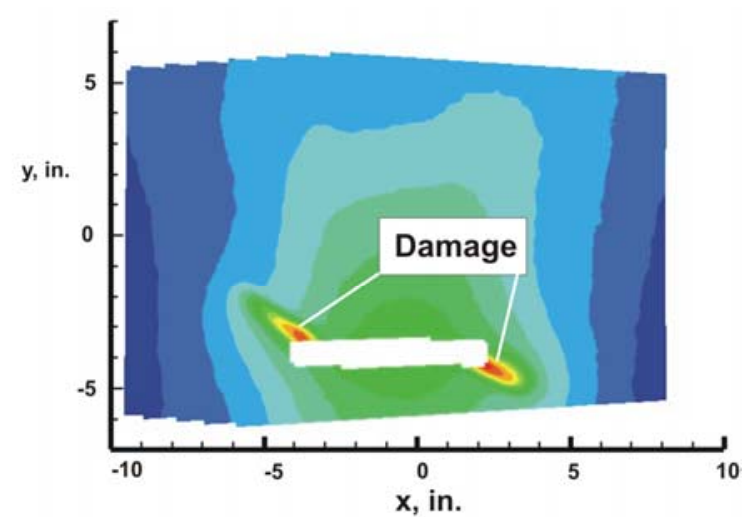

b. $\mathrm{Ny}=\mathbf{5 . 8 2} \mathrm{kips} / \mathrm{in}$.

Figure 21. Measured delamination/damage at end of slot at loads shown. 


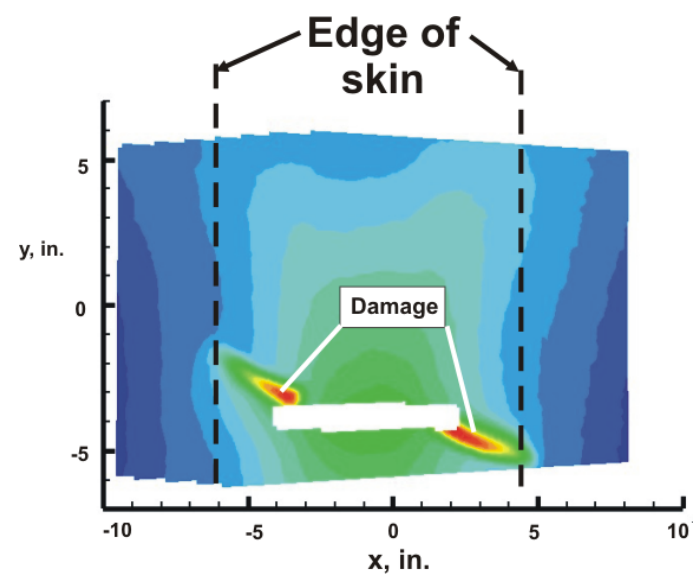

Ny $=7.51 \mathrm{kips} / \mathrm{in}$.

Figure 22. Measured damage propogation in panel TP-7 prior to failure.

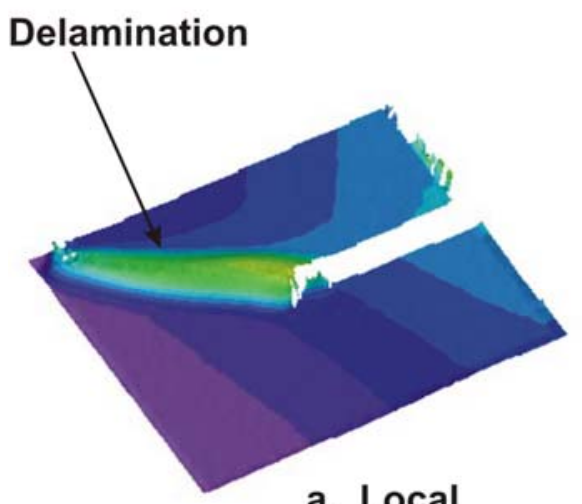

a. Local

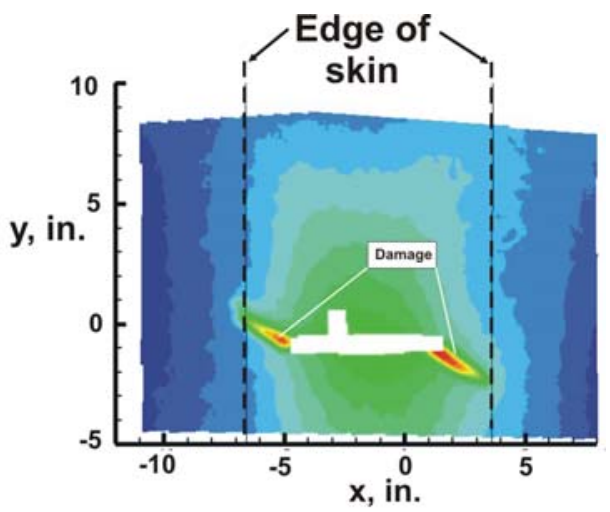

b. Global

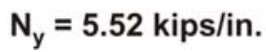

Figure 23. Local and global view of measured delamination on TP-4 at $\mathrm{N}_{\mathrm{y}}=5.52 \mathrm{kips} / \mathrm{in}$.

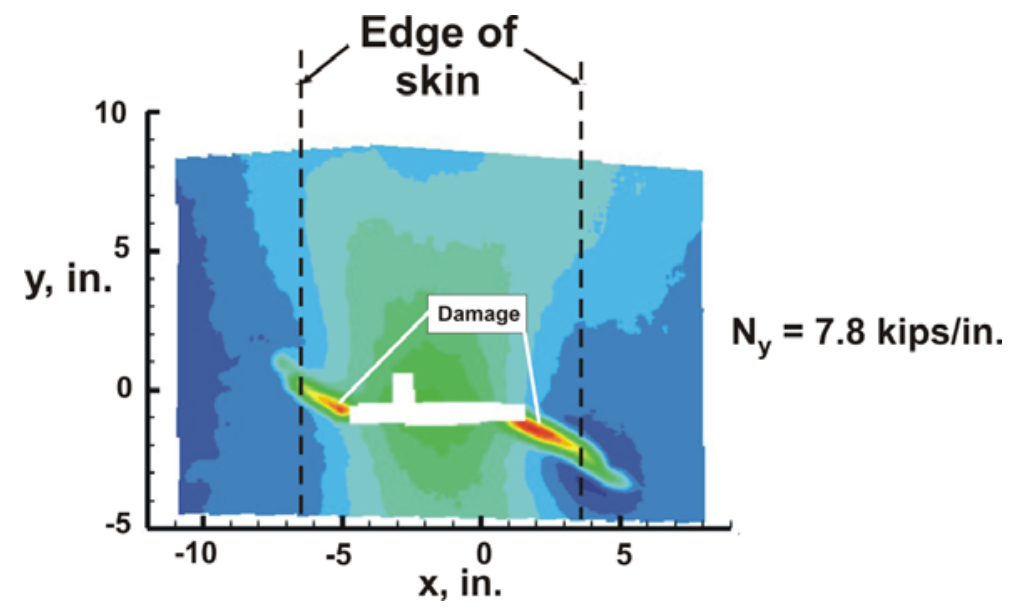

Figure 24. Measured out-of-plane displacements of TP-4 at near failure. 


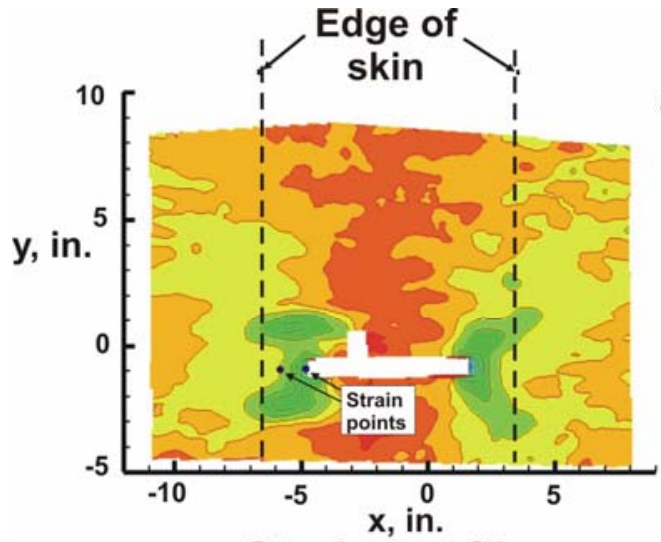

a. Strain profile of Panel TP-4

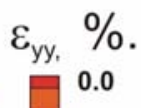

$-0.5$

$-1.0$

$N_{y}=5.6$ kips/in.

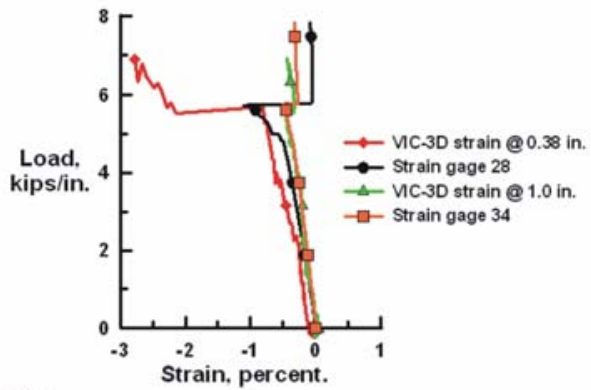

b. Strains at points shown.

Figure 25. Measured axial strains $\left(\varepsilon_{y y}\right)$ on panel TP-4..

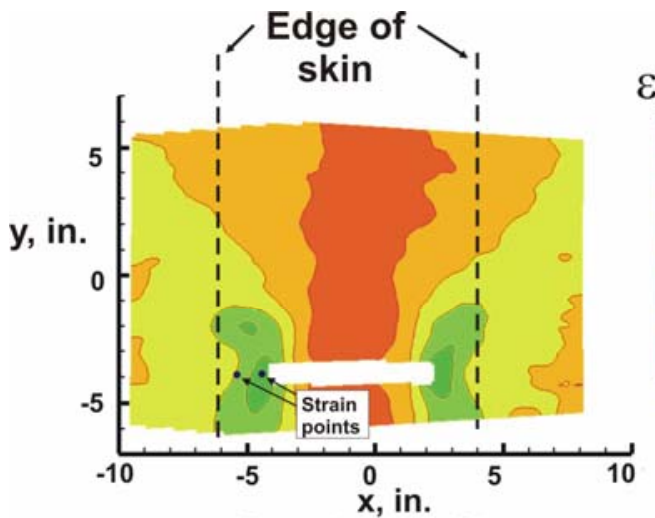

a. Strain profile of Panel TP-7

$$
\varepsilon_{\mathrm{yy},} \%
$$
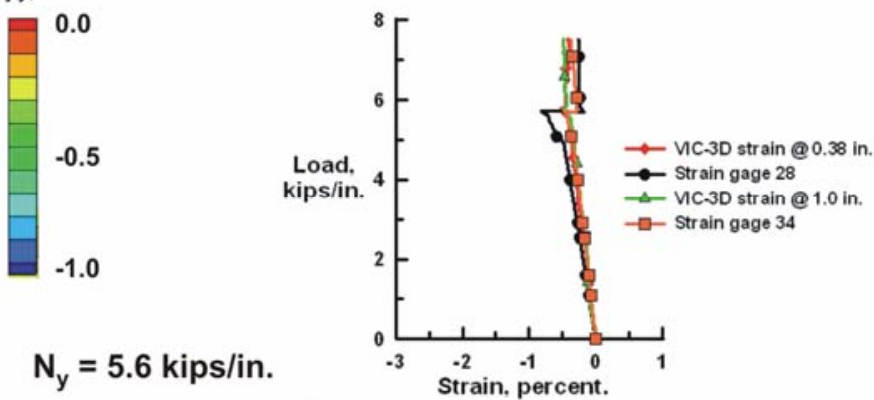

b. Strains at points shown.

Figure 26. Measured axial strains $\left(\varepsilon_{y y}\right)$ in the skin of panel TP-7.
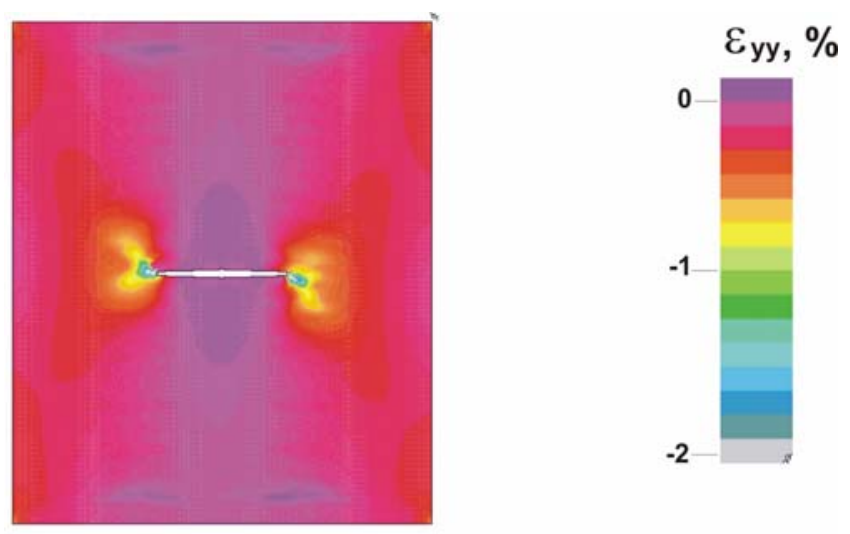

$$
N_{y}=5.58 \text { kips/in. }
$$

Figure 27. Predicted axial strains in Horizontal cut panel at a load of $\mathrm{Ny}=5.59$ kips/in. 


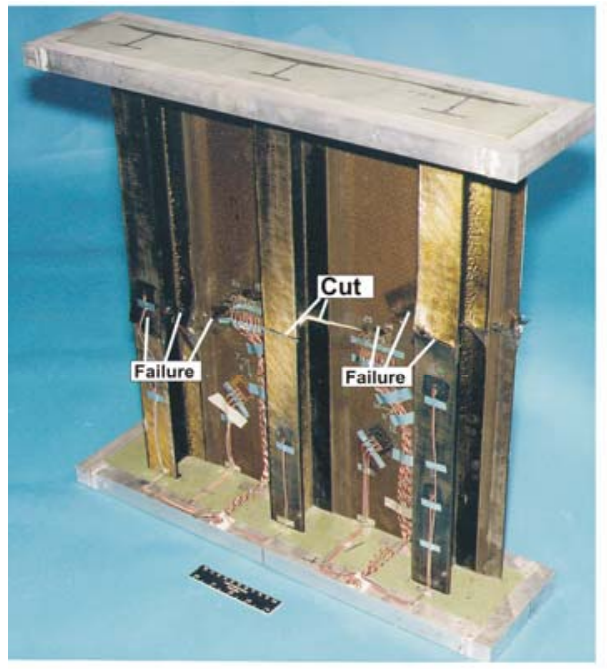

a. Stringer side

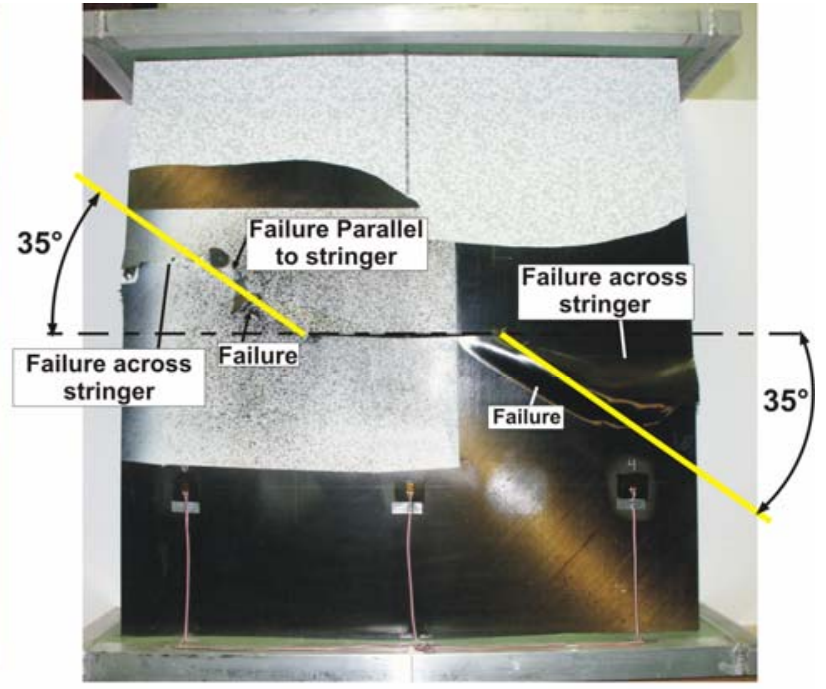

b. Skin side

Figure 28. Failed Horizontal cut panel.

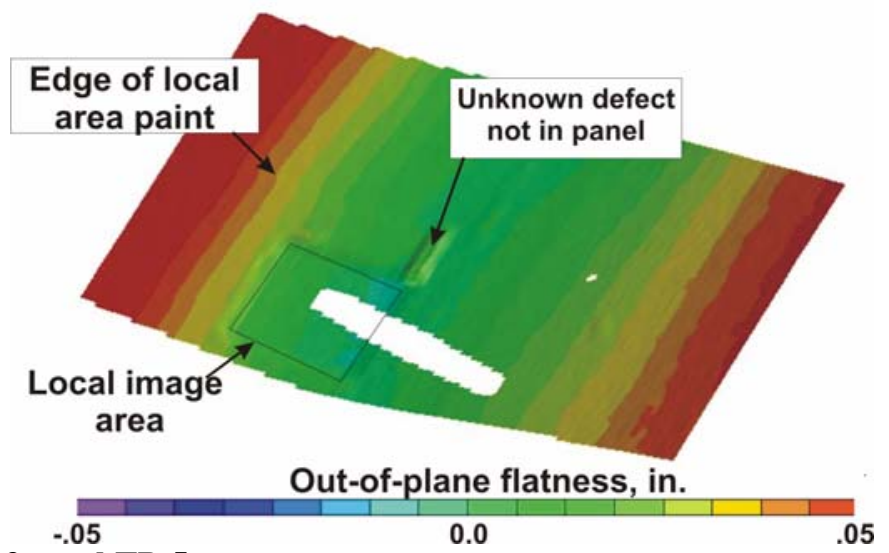

Figure 29. Profile of panel TP-5.

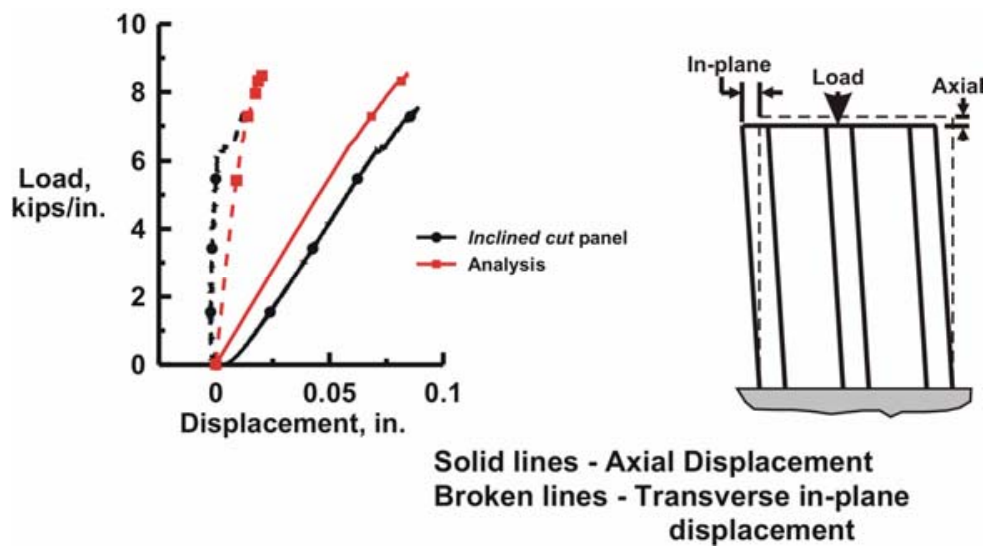

Figure 30. Axial and transverse in-plane displacements as a function of applied load. 


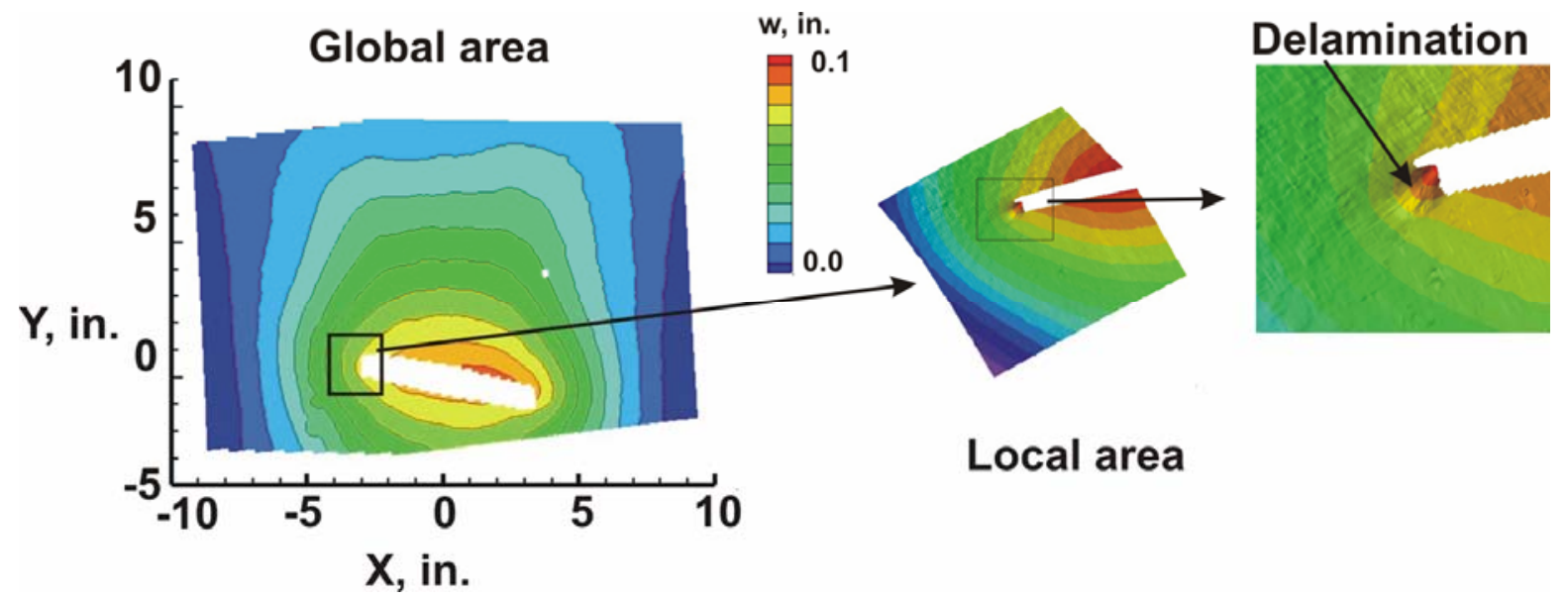

Figure 31. Measured delamination at end of slot in Inclined cut panel at a load of $\mathbf{N}_{\mathrm{y}}=6.32 \mathrm{kips}$./in.

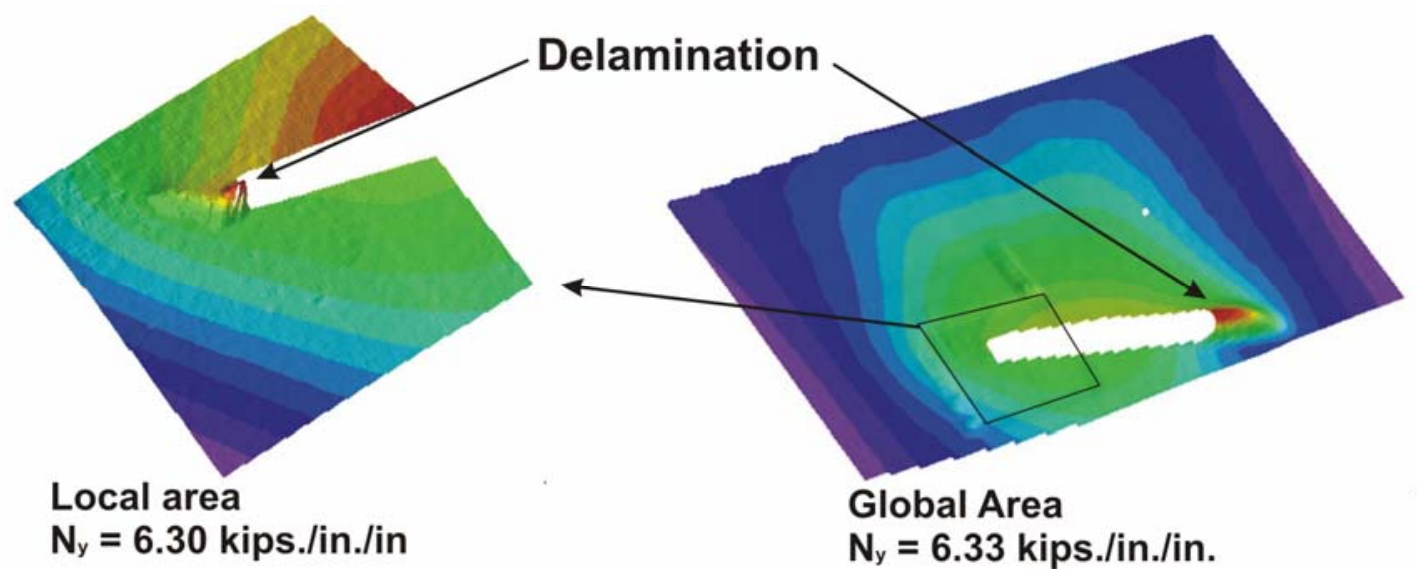

Figure 32. Measured initial failures of Inclined cut panel.

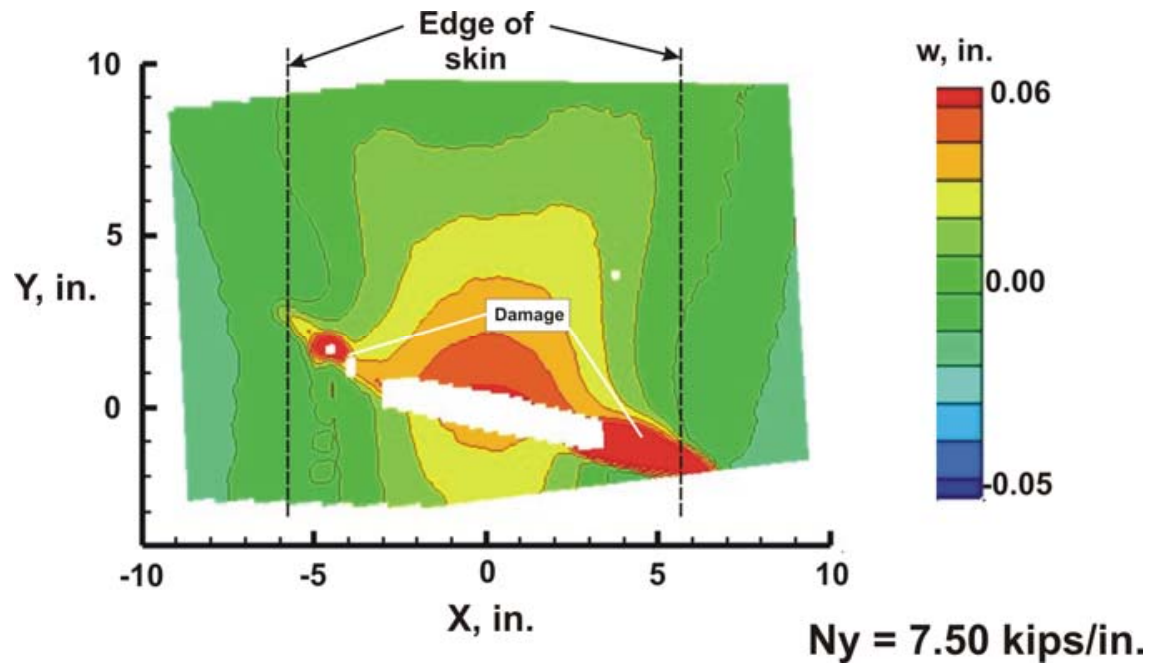

Figure 33. Measured out-of-plane displacements of Inclined cut panel at near failure. 


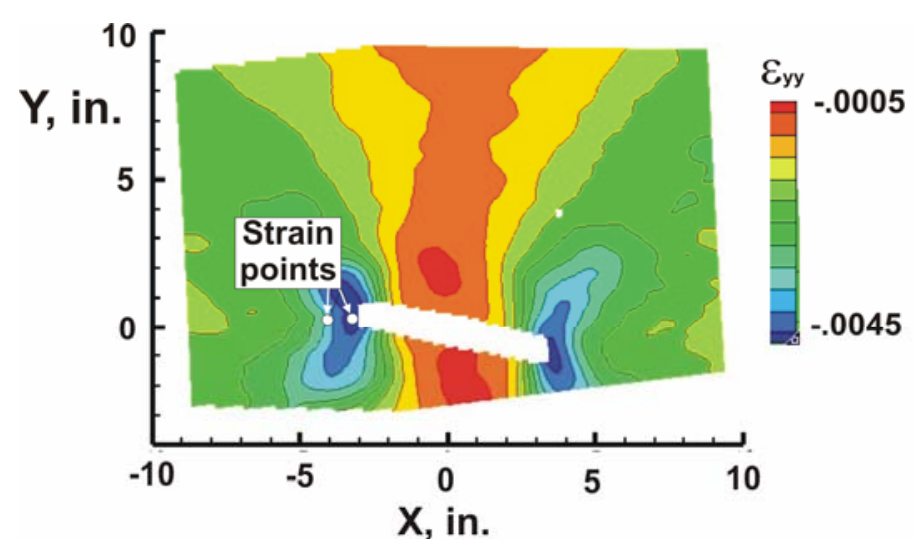

a. Strain profile at $\mathrm{N}_{\mathrm{y}}=6.03 \mathrm{kips} / \mathrm{in}$.

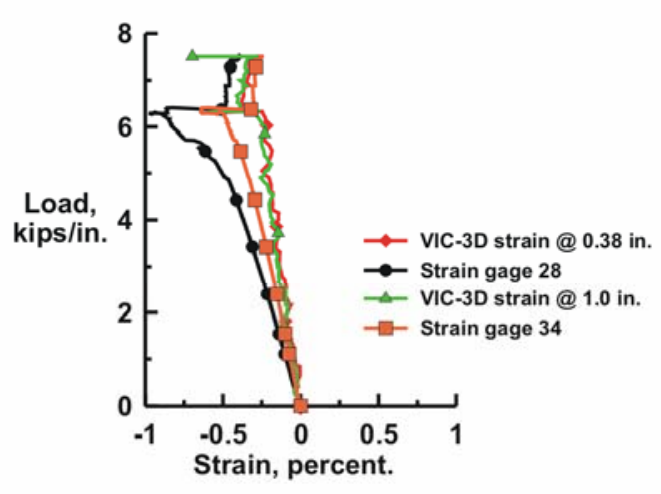

b. Strain at points shown

Figure 34, Axial strains in Inclined cut panel as determined by VIC-3D and strain gages.
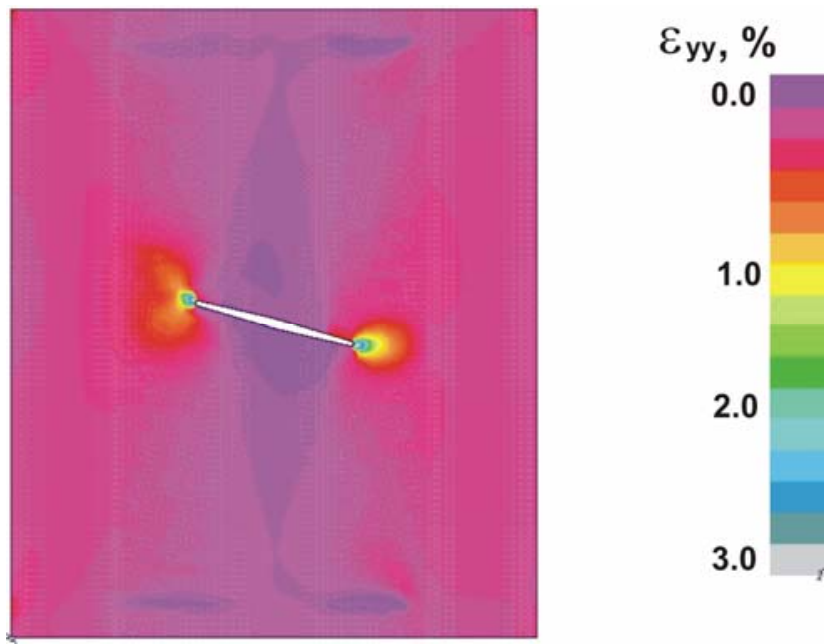

Figure 35. Predicted axial strains in Inclined cut panel at a load of $6.07 \mathrm{kips} / \mathrm{in}$.

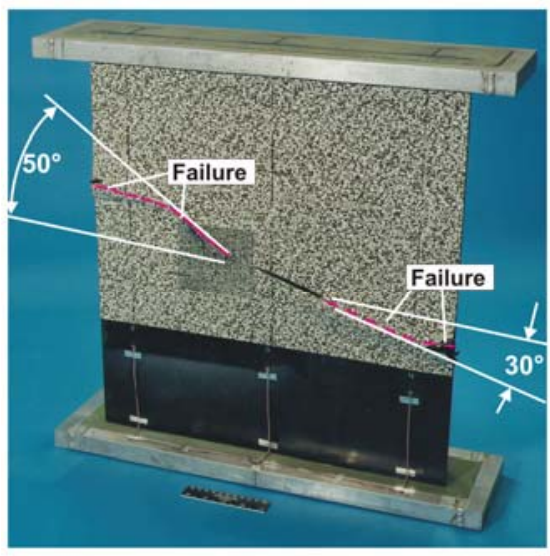

a. Skin side

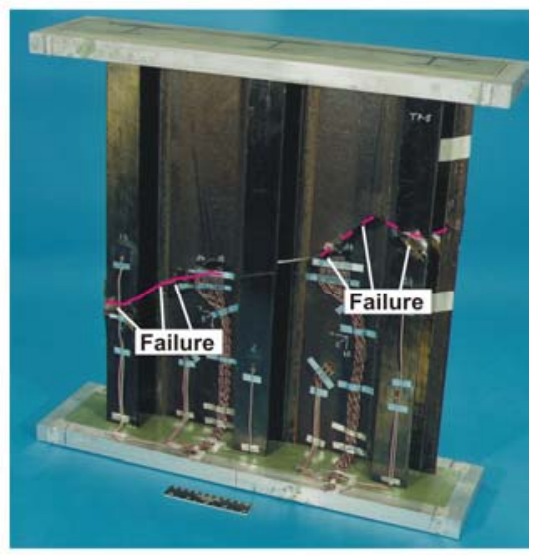

b. Stringer side

Figure 36. Failed Inclined cut panel. 